\title{
The clinical application of high-resolution peripheral computed tomography (HR-pQCT) in adults: state of the art and future directions
}

\author{
J.P. van den Bergh ${ }^{1,2,3} \cdot$ P. Szulc ${ }^{4} \cdot$ A.M. Cheung ${ }^{5} \cdot$ M. Bouxsein $^{6} \cdot$ K. Engelke $^{7} \cdot$ R. Chapurlat $^{4}$
}

Received: 14 December 2020 / Accepted: 6 May 2021 / Published online: 22 May 2021

(C) The Author(s) 2021

\begin{abstract}
High-resolution peripheral computed tomography (HR-pQCT) was developed to image bone microarchitecture in vivo at peripheral skeletal sites. Since the introduction of HR-pQCT in 2005, clinical research to gain insight into pathophysiology of skeletal fragility and to improve prediction of fractures has grown. Meanwhile, the second-generation HRpQCT device has been introduced, allowing novel applications such as hand joint imaging, assessment of subchondral bone and cartilage thickness in the knee, and distal radius fracture healing. This article provides an overview of the current clinical applications and guidance on interpretation of results, as well as future directions. Specifically, we provide an overview of (1) the differences and reference data for HR-pQCT variables by age, sex, and race/ethnicity; (2) fracture risk prediction using HR-pQCT; (3) the ability to monitor response of anti-osteoporosis therapy with HRpQCT; (4) the use of HR-pQCT in patients with metabolic bone disorders and diseases leading to secondary osteoporosis; and (5) novel applications of HR-pQCT imaging. Finally, we summarize the status of the application of HR-pQCT in clinical practice and discuss future directions. From the clinical perspective, there are both challenges and opportunities for more widespread use of HR-pQCT. Assessment of bone microarchitecture by HR-pQCT improves fracture prediction in mostly normal or osteopenic elderly subjects beyond DXA of the hip, but the added value is marginal. The prospects of HR-pQCT in clinical practice need further study with respect to medication effects, metabolic bone disorders, rare bone diseases, and other applications such as hand joint imaging and fracture healing. The mostly unexplored potential may be the differentiation of patients with only moderately low BMD but severe microstructural deterioration, which would have important implications for the decision on therapeutical interventions.
\end{abstract}

Keywords Fracture risk prediction $\cdot$ High-resolution peripheral quantitative computed tomography $(\mathrm{HR}-\mathrm{pQCT}) \cdot$ Metabolic bone disorders $\cdot$ Osteoporosis $\cdot$ Reference data

J.P. van den Bergh

jvdbergh@viecuri.nl

1 Department of Internal Medicine, VieCuri Medical Center, Venlo, The Netherlands

2 Department of Internal Medicine, Maastricht University Medical Center, Maastricht, The Netherlands

3 Faculty of Medicine, Hasselt University, Hasselt, Belgium

4 INSERM UMR 1033, Université de Lyon, Hôpital E Herriot, 69437 cedex 03 Lyon, France
5 Department of Medicine and Joint Department of Medical Imaging, University Health Network; and Department of Medicine and Centre of Excellence in Skeletal Health Assessment, University of Toronto, Toronto, Ontario, Canada

6 Center for Advanced Orthopedic Studies, Beth Israel Deaconess Medical Center and Department of Orthopedic Surgery, Harvard Medical School, Boston, MA, USA

7 Department of Medicine 3, FAU University Erlangen-Nürnberg and Universitätsklinikum Erlangen, Erlangen, Germany 


\section{Introduction}

Introduced over a decade ago, high-resolution peripheral quantitative computed tomography (HR-pQCT) is a lowdose X-ray-based imaging technique that was initially developed to image bone microarchitecture in vivo at peripheral skeletal sites to gain insight into pathophysiology underlying skeletal fragility and to improve prediction of fractures. The effective radiation dose from a standard HR-pQCT scan at the distal radius or tibia is $3-5 \mu \mathrm{Sv}$ depending on the scanner generation [1]. Compared to other common medical imaging techniques, this is considered a low radiation dose procedure. For example, a hip scan using dual-energy X-ray absorptiometry (DXA) has an effective dose of approximately $9 \mu \mathrm{Sv}$, a standard chest X-ray approximately $100 \mu \mathrm{Sv}$, and a hip CT scan 2-3 mSv [2, 3]. HR-pQCT assessments have been integrated in large epidemiological cohort studies such as MrOs, OFELY, CaMos, and the Framingham Osteoporosis Study. Notably, HR-pQCT has been studied in a number of metabolic bone disorders and clinical applications beyond osteoporosis. For example, it is used in rheumatoid arthritis to assess joint space width and bone erosions, in osteoarthritis of the knee and in some distal radius fracture healing studies. This article provides an overview of current clinical applications and guidance on interpretation of results and outlines obstacles and necessary steps to facilitate a broader clinical application of HR-pQCT beyond current, mostly research-focused use. The work is a product of a joint IOF-ASBMR-ECTS working group, which met in person and by teleconference over several years to produce this document.

\section{Bone density and architecture of distal forearm and distal tibia}

\section{Differences and reference data by age and sex}

Significant age-related differences in volumetric bone mineral density (vBMD), trabecular structure, cortical thickness (Ct.Th), and cortical porosity (Ct.Po) have been observed in men and premenopausal and postmenopausal women, in cross-sectional analyses from population-based cohorts. Age-related differences in total, trabecular, and cortical BMD (Tt.BMD, Tb.BMD, and Ct.BMD) of the radius are summarized in Table 1 and microarchitectural parameters in Table 2 as absolute values and percent differences between young normal (age 20-30) and elderly subjects (age 80 or 90) $[4-9,11,13]$. Dalzell et al. calculated age-related T scores for vBMD and Ct.Th [6]. For the other studies, T scores shown in Table 1 were calculated from BMD values and standard deviations of young normal if available. According to the WHO definition, only DXA-based T scores can be used for the diagnosis of osteoporosis; thus, these HR-pQCT T scores should not be considered for application in clinical practice. For comparison, T scores of ultradistal radius aBMD (by dualenergy X-ray absorptiometry (DXA)) reference values (Hologic) for men and women are also shown in Table 1. Data from several other papers [14-16] that have reported age-related changes, but for different age ranges, or in different format, are not included in the two tables.

In women, Tt.BMD, Ct.BMD, and Tb. BMD at the radius decreased on average by $33 \%, 16 \%$, and $29 \%$ between age 20-30 and age 80-90, respectively. For the same age range, corresponding average decreases for men were $22 \%, 11 \%$, and $17 \%$, respectively. Decrease of ultradistal radius DXA aBMD for reference data used by Hologic, which approximately corresponds to Tt.BMD, was comparable to HRpQCT for women (29\%) and men (18\%). There are large differences among studies, demonstrating that interpretation of age-related changes from cross-sectional studies must be done with caution. All studies listed in Tables 1 and 2 are based on cross-sectional data with the exception of Burt et al. [7]. Moreover, apart from the Brazilian study of Alvarenga et al. [8] and the Chinese studies of Zhu and Hung $[9,10]$, the studies listed in Tables 1 and 2 were conducted in Europe or North America with the first-generation HR-pQCT scanner (XtremeCT I, Scanco, Switzerland).

Young men had a higher trabecular bone volume fraction (Tb.BV/TV) due to more numerous thicker trabeculae than women, in both radius and tibia $[5,6,11]$. Young men also had higher Ct.Po compared to women and a larger cross sectional total (Tt.Ar) and cortical area (Ct.Ar) and a thicker cortex (Ct.Th) in the radius and tibia [4-6], though sex differences were not always significant for Ct.Th $[5,6,11]$. Estimated failure load was significantly higher in young men compared to women at both sites [4,5].

Similar to vBMD, age-related percent increases or decreases of the structural parameters were larger for women than for men. In general, the pattern of bone impairment differed between cortical and trabecular compartments during ageing. In both sexes and consistent with the age-related decrease in Tb.BMD, older individuals had a lower BV/TV at the radius and tibia. This was accompanied by a reduction in trabecular number (Tb.N) and thickness (Tb.Th) and increase in trabecular spacing (Tb.Sp) that were paralleled by an agerelated decline in Ct.Th. and an increase of Ct.Po at the distal radius and tibia $[4-6,11]$.

In the cross-sectional studies, the specific pattern of sexand site-related age dependency of the various HR-pQCT parameters varies among studies. For example in the CaMOS population, BV/TV tended to remain stable until age 50 in men and women and to decrease thereafter at the distal radius, whereas it decreased as soon as early adulthood at the distal tibia [4]. In contrast, in a British population sample, Dalzell et al. reported a more linear decrease of BV/TV over the age range 20 to 80 years in the radius as well [6]. In a Danish 
Table 1 Total, cortical, and trabecular volumetric BMD from first-generation distal radius HR-pQCT and ultra distal radius aBMD from DXA in women and men

\begin{tabular}{|c|c|c|c|c|c|c|c|}
\hline & & YN mean & YN SD & Mean at age 80 & \%Change & T score ${ }^{3}$ & Average \%change \\
\hline \multicolumn{8}{|c|}{ HR-pQCT female } \\
\hline \multirow[t]{7}{*}{ Tt.BMD } & Macdonald [4] & 319.7 & 60.8 & $209.1^{1}$ & -34.6 & -1.8 & \\
\hline & Hansen [5] & 342.0 & 72.0 & 231.0 & -32.5 & -1.5 & \\
\hline & Dalzell [6] & 350.9 & & 177.8 & -49.3 & -3.3 & \\
\hline & Burt [7] & 333.0 & & 264.0 & -20.7 & & \\
\hline & Alvarenga [8] & 331.0 & & $268.0^{2}$ & -19.0 & & \\
\hline & Hung [9] & 385.0 & & $241.0^{1}$ & -37.4 & & \\
\hline & Zhu [10] & 331.0 & & 268.0 & -19.0 & & -32.7 \\
\hline \multirow[t]{8}{*}{ Ct.BMD } & Macdonald [4] & 835.6 & 56.0 & $639.6^{1}$ & -23.5 & -3.5 & \\
\hline & Hansen [5] & 898.0 & 49.0 & 767.0 & -14.6 & -2.7 & \\
\hline & Khosla [11] & 893.0 & 45.2 & $700.3^{1}$ & -21.6 & -4.3 & \\
\hline & Dalzell [6] & 938.5 & & 664.4 & -29.2 & -5.4 & \\
\hline & Burt [7] & 955.0 & & 888.0 & -7.0 & & \\
\hline & Alvarenga [8] & 1017.0 & & $925.0^{2}$ & -9.0 & & \\
\hline & Hung [9] & 1030.0 & & $915.0^{1}$ & -11.2 & & \\
\hline & Zhu [10] & 1016.4 & & 915.0 & -10.0 & & -15.9 \\
\hline \multirow[t]{6}{*}{ Tb.BMD } & Hansen [5] & 160.0 & 36.0 & 116.0 & -27.5 & -1.2 & \\
\hline & Dalzell [6] & 157.0 & & 125.0 & -20.4 & -1.0 & \\
\hline & Burt [7] & 176.0 & & 135.0 & -23.3 & & \\
\hline & Alvarenga [8] & 172.0 & & $137.0^{2}$ & -20.3 & & \\
\hline & Hung [9] & 170.0 & & $100.0^{1}$ & -41.2 & & -29.0 \\
\hline & Zhu [10] & 164.7 & & 105.0 & -36.2 & & \\
\hline \multicolumn{8}{|c|}{ DXA ultradistal radius white female } \\
\hline aBMD & ref Data Hologic & 0.442 & 0.058 & 0.314 & -29.0 & -2.2 & \\
\hline \multicolumn{8}{|c|}{ HR-pQCT male } \\
\hline \multirow[t]{5}{*}{ Tt.BMD } & Macdonald [4] & 350.2 & 11.3 & $242.9^{1}$ & -30.6 & -9.5 & \\
\hline & Hansen [5] & 354.0 & 53.0 & 321.0 & -9.3 & -0.6 & \\
\hline & Dalzell [6] & 395.2 & & 261.4 & -33.9 & -2.0 & \\
\hline & Burt [7] & 355.0 & & 297.0 & -16.3 & & \\
\hline & Zhu [10] & 384.2 & & 314.3 & -18.2 & & -21.7 \\
\hline \multirow[t]{5}{*}{ Ct.BMD } & Macdonald [4] & 785.6 & 62.8 & $670.7^{1}$ & -14.6 & -1.8 & \\
\hline & Hansen [5] & 873.0 & 42.0 & 850.0 & -2.6 & -0.5 & \\
\hline & Khosla [11] & 850.3 & 38.0 & $716.6^{1}$ & -15.7 & -3.5 & \\
\hline & Dalzell [6] & 937.0 & & 763.0 & -18.6 & -3.9 & \\
\hline & Zhu [10] & 969.3 & & 930.0 & -4.1 & & -11.1 \\
\hline \multirow[t]{4}{*}{ Tb.BMD } & Hansen [5] & 199.0 & 33.0 & 165.0 & -17.1 & -1.0 & \\
\hline & Dalzell [6] & 193.0 & & 170.0 & -11.9 & -1.4 & \\
\hline & Burt [7] & 226.0 & & 186.0 & -17.7 & & \\
\hline & Zhu [10] & 197.9 & & 155.2 & -21.6 & & -17.1 \\
\hline \multicolumn{8}{|c|}{ DXA ultradistal radius female } \\
\hline aBMD & ref Data Hologic & 0.544 & 0.06 & 0.445 & -18.2 & -1.7 & \\
\hline
\end{tabular}

\% Change: percentage changes between young normal and subjects at age 80 of vBMD, the distal radius (HR-pQCT), and a BMD of the ultradistal radius (DXA). YN: young normal (age 25-30). Mean: mean BMD values for given age. SD: population standard deviation. \%Change: average change of study results for the given vBMD value. Ethnicities: Macdonald and Burt: participants from the Calgary, Alberta, cohort of the Canadian Multicentre Osteoporosis Study (CaMos); Hansen: subjects recruited via the Danish Civil Registration System; Dalzell: primary care patients from Norfolk, England; Alvarenga: employees of the University of São Paulo, Brazil; Khosla: random sample of Rochester, MN, US residents; Zhu and Hung: community dwelling/ambulatory Chinese from Hong Kong. For the other studies, T scores were calculated from BMD values and standard deviations of young normal

${ }^{1}$ Mean at age 90

${ }^{2}$ Median instead of mean values were published in this study

${ }^{3}$ Dalzell et al. have calculated age-related T scores for vBMD and Ct.Th [6]

population, Hansen et al. reported a linear decrease of BV/TV over the full age range for women and men in the radius, but in the tibia, they observed a linear decrease until age 50 in women and age 60 in men followed by a relatively small decrease afterwards [5]. Similar differences in age-related patterns of HR-pQCT parameters were found for Tb.Th in women [1-3] and men $[1,3,11]$. Ct.BMD at the radius and tibia remained relatively stable until the menopausal transition and until the age of 60 in men and declined thereafter $[5,6,11]$. The absolute increase in Ct.Po accelerated after age 50-60 and paralleled the decrease in Ct.BMD [16, 17]. On a percentage base, the maximum increase in Ct.Po at the radius probably 
occurs between ages 50 and 60 , with a median yearly increase of $7.1 \%$ in women and $2.8 \%$ in men compared to $0.35 \%$ in premenopausal women $[18,19]$.

There are three studies assessing age-related changes with longitudinal HR-pQCT measurements, of 1-, 3-, and 5 -year duration, in populations 20 to 80 years old [7, 19, 20]. Consistent with cross-sectional studies, Burt et al. showed an increase in trabecular area (Tb.Ar) and Ct.Po with decreases in Tt.BMD, Ct.BMD, Ct.Th, and Ct.Ar in both sexes over 5 years [7]. Tb.N decreased after age 50 [7, 19, 20]. However, no significant changes in Tb.Th and separation ( $\mathrm{Tb} . \mathrm{Sp}$ ) were found in the 5-year study of Burt et al., in contrast to Kawalik et al. [20], but this study only included postmenopausal women and the duration was only 1 year. Between age 40 and 70 , a small increase (0.4 to $0.7 \%$ per year) in bone strength was observed, possibly because of the increase in bone size and lack of trabecular bone changes, which was more likely to occur in males than females and at the tibia rather than the radius [7]. When comparing models predicting rate of change from cross-sectional data to the longitudinal change, Burt et al. reported similar outcomes for Tt.BMD and Ct.Th at the radius and Ct.BMD at the tibia, but changes of other parameters may be overestimated from cross-sectional data by onefold to fivefold [7].

Normative HR-pQCT data are needed to compare an individual or a population of interest relative to a reference cohort. Some normative datasets have been published for the firstgeneration HR-pQCT for Caucasian and mixed Caucasian and Asian adolescent populations [21,22] and adult populations in America, Europe, and China [5, 8, 10, 11, 23]. Recently, normative data have been published for the second-generation HR-pQCT for Chinese [24] and Canadian men and women [25].

\section{Differences by body composition}

Evans et al. reported that obese individuals may have higher Tt.BMD and Tb.BMD than their normal-weight counterparts. Tb.N, Ct.Th, and Ct.TMD were also higher in obese people, and Ct.Po was lower [26]. The magnitude of the difference observed between obese and normal weight individuals using HR-pQCT was comparable to that observed using DXA, suggesting that the higher bone density in obesity is not solely an artifact resulting from greater soft tissue thickness [26]. However, higher absolute values of bone densities, cortical and trabecular architecture, and strength indices were not in proportion to the excess of BMI and particularly of fat mass in obese postmenopausal women [27]. This absence of bone adaptation to higher body weight has also been observed in obese adolescent girls [28]. In addition, long-term and recent weight loss have been associated with lower cortical density and thickness, higher cortical porosity, and lower trabecular density and number [29].

\section{Differences by race/ethnic origin}

Several studies have reported differences in HR-pQCT outcomes by race and ethnic origin. For example, a more favorable bone microarchitecture is seen in young adult black compared to white men and women. Specifically, black men and women have greater Ct.Ar, Tt.BMD, and Ct.Th and lower Ct.Po, with greater Tb.Th and Tt.BMD and higher $\mu$ FEAestimated failure load than white individuals [30]. Also, black individuals exhibit an enhanced plate-like morphology and greater trabecular axial alignment than white individuals [31]. Perimenopausal and postmenopausal black women have greater plate-like trabecular morphology and greater axial alignment of trabeculae, whereas white women have a more rod-like trabecular network [32]. These findings demonstrate that more favorable bone microarchitecture may contribute to the improved bone strength and lower fracture risk in black versus white individuals.

Asian young men have smaller bones, thicker and denser cortices, and more plate-like trabeculae than white young men, but biomechanical estimates of bone strength do not differ between groups [33]. Wang et al. observed that premenopausal Asian women have thicker cortices and thicker but fewer trabeculae than Caucasians [34], with higher estimates of bone stiffness/strength in $\mu$ FEA [35]. Premenopausal and postmenopausal Chinese American women have lower Ct.Po and greater cortical tissue mineral density (Ct.TMD) resulting in higher Ct.BMD compared to white women. The thicker and preserved cortical bone structure in Chinese American women may contribute to greater resistance to fracture compared to white women [36].

\section{HR-pQCT and fracture}

\section{Bone microarchitecture in individuals with prior fractures}

The majority of studies have shown poor bone microarchitecture in subjects with prior fractures independent of sex, age, fracture skeletal site, or baseline health status [37-49]. In older men, the presence of fragility fractures was also associated with lower Tb.N, Ct.Th, and Ct.BMD and increased Ct.Po $[50,51]$ and a conversion from plates into rods [52]. In a recent systematic review and meta-analysis, radial and tibial HR-pQCT parameters, including failure load, were significantly lower, ranging from -2.6 to $-12.6 \%$, in subjects with a prior fracture [53]. 
Table 2 HR-pQCT (first generation) microarchitectural parameters and changes in women and men with ageing

\begin{tabular}{|c|c|c|c|c|c|c|c|}
\hline & & YN mean & YN SD & Mean at age 80 & \%Change & T score ${ }^{2}$ & Average $\%$ change \\
\hline \multicolumn{8}{|l|}{ Women } \\
\hline \multirow[t]{5}{*}{$\mathrm{BV} / \mathrm{TV}$} & Macdonald [4] & 0.126 & 0.028 & $0.098^{1}$ & -22.22 & -1.0 & \\
\hline & Hansen [5] & 0.133 & 0.030 & 0.096 & -27.82 & -1.2 & \\
\hline & Khosla [11] & 0.141 & 0.028 & $0.102^{1}$ & -27.66 & -1.4 & \\
\hline & Dalzell [6] & 0.138 & & 0.132 & -4.35 & & \\
\hline & Hung [9] & 0.138 & & $0.074^{1}$ & -46.1 & & -25.6 \\
\hline \multirow[t]{5}{*}{ Tt.Ar } & Macdonald [4] & 262.8 & 42.7 & $266.7^{1}$ & 1.48 & 0.1 & \\
\hline & Hansen [5] & 254.0 & 44.0 & 269.0 & 5.91 & 0.3 & \\
\hline & Dalzell [6] & 241.0 & & 309.1 & 28.27 & & \\
\hline & Burt [7] & 190.0 & & 185.0 & -2.63 & & \\
\hline & Zhu [10] & 197.1 & & 206 & 4.52 & & 7.5 \\
\hline \multirow[t]{6}{*}{ Tb.N } & Macdonald [4] & 1.95 & 0.210 & $1.54^{1}$ & -21.03 & -2.0 & \\
\hline & Hansen [5] & 1.93 & 0.260 & 1.75 & -9.33 & -0.7 & \\
\hline & Khosla [11] & 2.64 & 0.170 & $2.29^{1}$ & -13.26 & -2.1 & \\
\hline & Dalzell [6] & 2.10 & & 1.82 & -12.98 & & \\
\hline & Zhu [10] & 1.72 & & 1.21 & -29.65 & & \\
\hline & Hung [9] & 1.68 & & $1.18^{1}$ & -29.7 & & -19.3 \\
\hline \multirow[t]{6}{*}{ Tb.Th } & Macdonald [4] & 0.064 & 0.011 & $0.063^{1}$ & -1.56 & -0.1 & \\
\hline & Hansen [5] & 0.069 & 0.013 & 0.057 & -17.39 & -0.9 & \\
\hline & Khosla [11] & 0.053 & 0.009 & $0.043^{1}$ & -18.87 & -1.1 & \\
\hline & Dalzell [6] & 0.061 & & 0.042 & -31.15 & & \\
\hline & Zhu [10] & 0.195 & & 0.195 & 0.00 & & \\
\hline & Hung [9] & 0.09 & & $0.077^{1}$ & -14.3 & & $-16.7^{2}$ \\
\hline \multirow[t]{6}{*}{$\mathrm{Tb} . \mathrm{Sp}$} & Macdonald [4] & 0.454 & 0.065 & $0.606^{1}$ & 33.48 & 2.3 & \\
\hline & Hansen [5] & 0.448 & 0.453 & 0.558 & 24.55 & 0.2 & \\
\hline & Khosla [11] & 0.327 & 0.031 & $0.399^{1}$ & 22.02 & 2.3 & \\
\hline & Dalzell [6] & 0.446 & & 0.575 & 28.92 & & \\
\hline & Zhu [10] & 0.547 & & 0.863 & 57.77 & & \\
\hline & Hung [9] & 0.501 & & $0.764^{1}$ & 52.5 & & 36.5 \\
\hline \multirow[t]{5}{*}{ Ct.Ar } & Macdonald [4] & 62.8 & 10.3 & $50.8^{1}$ & -19.11 & -1.2 & \\
\hline & Hansen [5] & 57.0 & 11.0 & 39.0 & -31.58 & -1.6 & \\
\hline & Burt [7] & 51.0 & & 41.0 & -19.61 & & \\
\hline & Zhu [10] & 55.1 & & 41.4 & -24.86 & & \\
\hline & Hung [9] & 55.1 & & $45.5^{1}$ & -17.4 & & -22.5 \\
\hline \multirow[t]{4}{*}{ Ct.Po } & Macdonald [4] & 6.20 & 3.10 & $16.2^{1}$ & 161.29 & 3.2 & \\
\hline & Burt [7] & 0.8 & & 2.9 & 253.01 & & \\
\hline & Zhu [10] & 0.4 & & 2.8 & 600.00 & & \\
\hline & Hung [9] & 0.774 & & $2.3^{1}$ & 198 & & 303 \\
\hline \multirow[t]{7}{*}{ Ct.Th } & Macdonald [4] & 1.060 & 0.190 & $0.820^{1}$ & -22.64 & -1.3 & \\
\hline & Hansen [5] & 0.940 & 0.200 & 0.710 & -24.47 & -1.2 & \\
\hline & Khosla [11] & 0.825 & $0.136^{1}$ & 0.388 & -52.97 & -3.2 & \\
\hline & Dalzell [6] & 0.884 & & 0.309 & -65.05 & -4.6 & \\
\hline & Burt [7] & 0.920 & & 0.780 & -15.22 & & \\
\hline & Zhu [10] & 1.043 & & 0.76 & -27.13 & & \\
\hline & Hung [9] & 1.3 & & $1.06^{1}$ & -18.8 & - & -32.3 \\
\hline \multicolumn{8}{|l|}{ Men } \\
\hline \multirow[t]{3}{*}{$\mathrm{BV} / \mathrm{TV}$} & Macdonald [4] & 0.169 & $0.030^{1}$ & 0.126 & -25.44 & -1.4 & \\
\hline & Hansen [5] & 0.165 & 0.028 & 0.137 & -16.97 & -1.0 & \\
\hline & Khosla [11] & 0.178 & $0.031^{1}$ & 0.131 & -26.40 & -1.5 & \\
\hline
\end{tabular}


Table 2 (continued)

\begin{tabular}{|c|c|c|c|c|c|c|c|}
\hline & & YN mean & YN SD & Mean at age 80 & \%Change & T score ${ }^{2}$ & Average \%change \\
\hline & Dalzell [6] & 0.165 & & 0.154 & -6.67 & & -18.9 \\
\hline \multirow[t]{5}{*}{ Tt.Ar } & Macdonald [4] & 349.0 & $56.4^{1}$ & 413.1 & 18.37 & 1.1 & \\
\hline & Hansen [5] & 358.0 & 61.0 & 362.0 & 1.12 & 0.1 & \\
\hline & Dalzell [6] & 296.3 & & 415.8 & 40.36 & & \\
\hline & Burt [7] & 272.0 & & 273.0 & 0.37 & & \\
\hline & Zhu [10] & 258 & & 280.2 & 8.60 & & 13.8 \\
\hline \multirow[t]{5}{*}{ Tb.N } & Macdonald [4] & 2.20 & $0.250^{1}$ & 1.92 & -12.68 & -1.1 & \\
\hline & Hansen [5] & 2.06 & 0.220 & 2.05 & -0.49 & 0.0 & \\
\hline & Khosla [11] & 2.60 & $0.250^{1}$ & 2.77 & 6.54 & 0.7 & \\
\hline & Dalzell [6] & 2.25 & & 2.13 & -5.16 & & \\
\hline & Zhu [10] & 1.75 & & 1.62 & -7.43 & & -3.8 \\
\hline \multirow[t]{5}{*}{ Tb.Th } & Macdonald [4] & 0.077 & $0.015^{1}$ & 0.065 & -15.58 & -0.8 & \\
\hline & Hansen [5] & 0.080 & 0.013 & 0.067 & -16.25 & -1.0 & \\
\hline & Khosla [11] & 0.068 & $0.008^{1}$ & 0.050 & -26.47 & -2.3 & \\
\hline & Dalzell [6] & 0.074 & & 0.090 & 21.62 & & \\
\hline & Zhu [10] & 0.214 & & 0.205 & -4.21 & & $-9.2^{2}$ \\
\hline \multirow[t]{5}{*}{$\mathrm{Tb} . \mathrm{Sp}$} & Macdonald [4] & 0.382 & $0.049^{1}$ & 0.431 & 12.83 & 1.0 & \\
\hline & Hansen [5] & 0.406 & 0.408 & 0.436 & 7.39 & 0.1 & \\
\hline & Khosla [11] & 0.320 & $0.041^{1}$ & 0.313 & -2.19 & -0.2 & \\
\hline & Dalzell [6] & 0.376 & & 0.403 & 7.32 & & \\
\hline & Zhu [10] & 0.528 & & 0.602 & 14.02 & & 7.9 \\
\hline \multirow[t]{4}{*}{ Ct.Ar } & Macdonald [4] & 86.6 & $14.6^{1}$ & 79.1 & -8.66 & -0.5 & \\
\hline & Hansen [5] & 75.0 & 12.0 & 74 & -1.33 & -0.1 & \\
\hline & Burt [7] & 68.0 & & 59.0 & -13.24 & & \\
\hline & Zhu [10] & 68.2 & & 63.9 & -6.30 & & -7.4 \\
\hline \multirow[t]{3}{*}{ Ct.Po } & Macdonald [4] & 8.10 & $4.30^{1}$ & 15.7 & 94 & 1.8 & \\
\hline & Burt [7] & 1.92 & & 3.46 & 80 & & \\
\hline & Zhu [10] & 0.83 & & 4 & 382 & & 185 \\
\hline \multirow[t]{6}{*}{ Ct.Th } & Macdonald [4] & 1.250 & $0.250^{1}$ & 1.000 & -20.00 & -1.0 & \\
\hline & Hansen [5] & 1.020 & 0.170 & 1.040 & 1.96 & 0.1 & \\
\hline & Khosla [11] & 0.852 & $0.176^{1}$ & 0.522 & -38.73 & -1.9 & \\
\hline & Dalzell [6] & 1.050 & & 0.544 & -48.19 & -4.6 & \\
\hline & Burt [7] & 1.010 & & 0.920 & -8.91 & & \\
\hline & Zhu [10] & 1.102 & & 1.047 & -4.99 & & -19.8 \\
\hline
\end{tabular}

$\%$ change: percentage changes between young normal and subjects at age 80 of cortical and trabecular [12] architecture of the radius (HR-pQCT). YN: young normal (age 25-30). Mean: mean value of microarchitectural parameters for given age. SD: population standard deviation. \%Change: average change of study results for the given microarchitectural parameter. Information on ethnicity, see Table 1. Studies of Burt [7] (longitudinal analysis) and Macdonald [4] (cross-sectional analysis) used the same population, but because of different analyses, both studies contributed to the average values

${ }^{1}$ Mean at age 90

${ }^{2}$ Dalzell et al. have calculated age-related T scores for vBMD and Ct.Th [6]. For the other studies, T scores were calculated from BMD values and standard deviations of young normal

\section{Bone microarchitecture and bone strength as predictors of incident fractures}

Six individual studies demonstrated that HR-pQCT variables could predict incident fractures in postmenopausal women and older men [54-59]. In the three studies with postmenopausal women (mean age of 65 to 68 years), follow-up periods were 5, 9.4, and 5 years. The cohorts consisted of 740,598 , and 163 women, with a fracture incidence of $9.2 \%, 22.9 \%$, and $13.5 \%$. The strongest prediction was found for Tt.BMD and Tb.N at the distal radius [54-56]. In the three studies with older men (mean age 74 to 84 years), 
follow-up varied between 1.7 years and 5.3 years, but the number of fractures was relatively low $(n=71-108,3.6-$ $15.6 \%$ ) [57-59]. The strongest association was found for Tt.BMD and Tb.N at the radius $[58,59]$ and tibial Ct.Ar and mass [57].

The Bone Microarchitecture International Consortium (BoMIC) pooled HR-pQCT data of 7254 participants $(66 \%$ women and $34 \%$ men, with a mean age of 69 years) from eight cohorts assembled in the USA (Framingham, Mayo Clinic) [60], France (QUALYOR) [61], STRAMBO [62], OFELY [40], Switzerland (GERICO) [63], Canada (CaMos) [39], and Sweden (MrOS) [64] for a combined prospective analysis of incident fracture risk [65]. All HR-pQCT data were obtained with the XtremeCT I device. Within a mean follow-up of 4.6 years, 765 incident fractures occurred. Five hundred nine fractures (150 wrist, 122 spine, 68 hip, 63 humerus, and 362 other fractures) originated from falls from standing height or lower. After adjustment for age, sex, height, and cohort, Tt.BMD, Ct.BMD, Tb.BMD, and parameters of trabecular structure (Tb.N, Tb.Th, Tb.Sp) and of cortical morphology (Ct.Ar, Ct.Th, Ct.Po) measured at the distal tibia or distal radius were significant predictors of incident fracture with the exception of Ct.Po at the distal radius. Hazard ratios per $1 \mathrm{SD}$ decrease were highest (up to 1.75) for Tt.BMD, Tb.BMD, and Ct.Ar and varied from 1.12 to 1.58 for the other parameters.

Failure load calculated from $\mu \mathrm{FEA}$ at the distal radius and tibia also predicted the risk of fracture, with a HR of 2.13 and 2.40 per 1 SD decrease, respectively, but confidence intervals were about 3 times as wide as for the other parameters due to a smaller sample size for $\mu$ FEA. In sex-stratified analyses, results for incident fracture were largely similar in women and men, although effect sizes were somewhat attenuated in men. Additional adjustment for femoral neck aBMD by DXA or by FRAX score reduced the HRs, but generally, they remained significant with the exception of Ct.Th and Ct.Po measured at the tibia. These findings show that HR-pQCT measurements predict fracture risk independent of DXA-BMD of the hip. After adjustment for aBMD of the ultradistal radius by DXA (and not for aBMD of the hip), Tb.BMD (HR = 1.26) and Tb.N (HR $=1.18)$ remained significant predictors of incident fractures. It is interesting that the ultradistal aBMD adjustment eliminated the significance of all cortical parameters and even of bone strength. It is also important to note that for the firstgeneration XtremeCT device, Tb.BMD and Tb.N are the two primary measurements from which all other parameters of trabecular structure are derived. Therefore, results may be different for the second-generation HR-pQCT scanner.

In multivariate analyses with major osteoporotic fractures as outcome, the area under the curve (AUC) was used as performance criterion. Ct.BMD, Tb.N, and Tb.Sp of the radius slightly but significantly improved AUC from 0.73 for DXA aBMD of the hip alone to 0.75 , whereas in the tibia, cortical, and trabecular HR-pQCT parameters did not further improve the AUC of 0.72 for DXA aBMD of the hip alone. A recent report from the QUALYOR and OFELY cohorts revealed that a new measure capturing severe cortical and trabecular deterioration, the structural fragility score (SFS), predicts increased fracture risk irrespective of aBMD in women $\geq$ 70 years of age [66].

In summary, the BoMIC study suggests that the assessment of cortical and trabecular bone microarchitecture by HRpQCT could improve overall fracture prediction in mostly normal or osteopenic elderly subjects beyond DXA hip aBMD, but improvement in multivariate models was relatively small. When HR-pQCT indices or failure load were compared with femoral neck aBMD, the overall net reclassification improvement value varied between 17 and 21\% [65].

Thus, a potential use of HR-pQCT may be the differentiation of patients with severe microstructural deterioration, within osteopenic or osteoporotic BMD categories, which would have important implications for the decision on therapeutical interventions. Recently, it has been reported that in women with osteopenia, it is cost-effective to treat those with microstructural deterioration [67].

\section{HR-pQCT in monitoring response of anti-osteoporotic therapy}

The effect of several anti-osteoporotic drugs on HR-pQCT parameters has been studied (Table 3) [17, 68-81]. All studies have been performed in postmenopausal women, except for one small study in premenopausal women.

In the RCTs with oral bisphosphonates alendronate, risedronate, and ibandronate, no significant differences were found compared to placebo in HR-pQCT parameters after 12 to 31-month follow-up in postmenopausal women, except for a $1 \%$ higher Ct.BMD in the tibia with alendronate, a $5 \%$ higher Tt.BMD in the radius, a $2 \%$ higher Ct.BMD, and a $5 \%$ higher $\mathrm{Ct}$.Th in the tibia with ibandronate [68-71].

Strontium ranelate (SrRan) has been compared with alendronate, but not with placebo [72]. SrRan appeared to influence distal tibia and FEA-determined biomechanical parameters more than ALN. However, a possible artifactual contribution of strontium cannot be excluded.

After 12 months of treatment in postmenopausal women, Tt.BMD, Ct.BMD, and Tb.BMD, and Ct.Th were higher in women treated with denosumab or alendronate compared to placebo, mainly explained by a $1-2 \%$ decrease of Tt.BMD, Tb.BMD, and Ct.BMD in the placebo group versus $0-1 \%$ increase in the intervention groups [73]. In addition, Tt.BMD and Ct.BMD were greater with denosumab compared to alendronate, while Ct.Th was higher than PBO (2$3 \%$ ) in both intervention groups. 


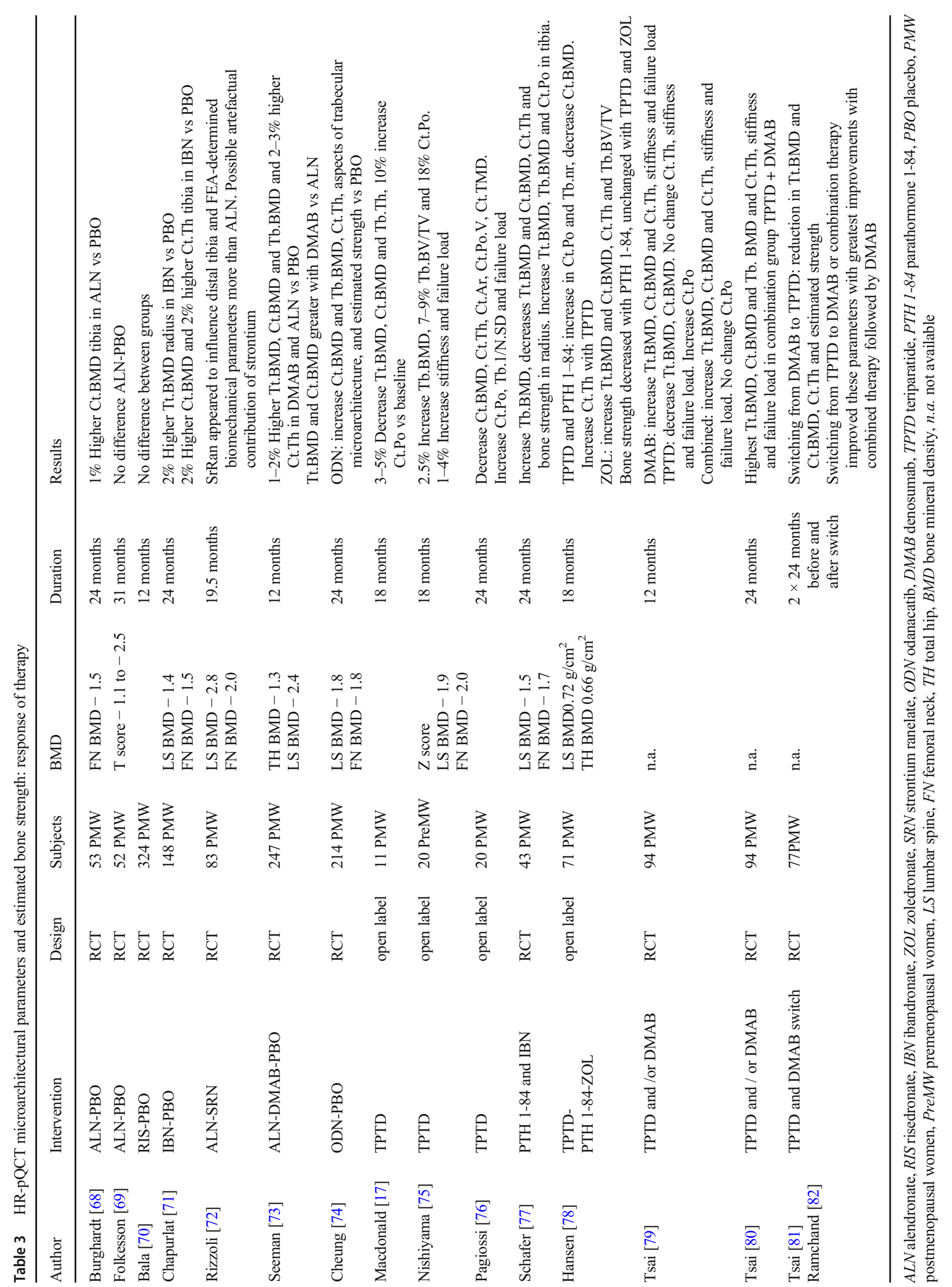


Compared to placebo, treatment with the cathepsin $\mathrm{K}$ inhibitor odanacatib led to increased Ct.BMD and Tb.BMD, $\mathrm{Ct}$.Th, and aspects of trabecular microarchitecture, and estimated strength was reported in a 2-year randomized controlled trial of 214 postmenopausal women. Treatment differences compared to placebo were $2-3 \%$ in the radius and tibia [74].

The small open-label studies with teriparatide showed a 3 to $5 \%$ decrease of Tt.BMD, Ct.BMD, and Tb.Th, with increased Ct.Po (up to $+10 \%$ ) and maintained or slightly increased $(+0.2 \%)$ bone strength $[17,76]$. One open-label study in premenopausal women showed an increased Tb.BMD (+ 2.5\%), trabecular plate bone volume fraction ( 7 to $9 \%$ ), and Ct.Po $(+18 \%)$, resulting in a 1 to $4 \%$ increased stiffness and failure load after 18 months of teriparatide treatment [75].

Compared to teriparatide, PTH 1-84 showed a comparable increase in Ct.Po and Tb.N and a decrease of Ct.BMD, although $\mathrm{Ct}$.Th increased with TPTD but not with PTH 1-84, while bone strength decreased with PTH 1-84 and was unchanged with TPTD after 18-month treatment in postmenopausal women [78]. In the same study, zoledronate $5 \mathrm{mg}$ infused once yearly resulted in 1 to $3 \%$ increased Tt.BMD and Ct.BMD, Ct.Th, and Tb.BV/TV, with unchanged bone strength. The combined treatment of PTH 1-84 with ibandronate resulted in differential effects in the radius and tibia, with an increase in Tb.BMD, decreases in Tt.BMD and Ct.BMD, Ct.Th, and bone strength in the radius, and increases in Tt.BMD, Tb.BMD, and Ct.Po with preserved bone strength in the tibia [77].

In the three studies comparing and combining teriparatide with denosumab of Tsai et al., Tt.BMD, Ct.BMD, Ct.Th, stiffness, and failure load increased in the denosumab-treated group. In the teriparatide group, Tt.BMD and Ct.BMD decreased, while Ct.Po increased, and there was no change in Ct.Th, stiffness, and failure load [79-81]. The highest Tt.BMD, Ct.BMD, and Tb.BMD, Ct.Th, stiffness, and failure load were found in the group with combined teriparatide and denosumab treatment during 24 months [80]. Switching after 2 years of denosumab treatment to teriparatide for 2 years resulted in a reduction in Tt.BMD, Ct.BMD, Ct.Th, and estimated strength. Switching from teriparatide to denosumab or combination therapy improved these parameters with greatest improvements with combined therapy followed by denosumab [81, 82].

So far, no HR-pQCT studies have reported treatment effects for abaloparatide and romosozumab, except for a small phase $1 \mathrm{~b}$ study with romosozumab administered for 3 months showing rapid and large improvements in Tb.BMD (+12\%), Ct.Th $(+13 \%)$, and stiffness $(+35 \%)$ [83].

In specific patient groups, treatment effects have been studied in case reports or in small studies, such as denosumab and zoledronate in kidney transplant recipients [84, 85], ibandronate or daily 1-hydroxycholecalciferol in Chinese systemic lupus patients [86], and zoledronate in men receiving androgen deprivation therapy [87].

In summary, treatment monitoring with HR-pQCT allows for separate analyses of trabecular and cortical architectural parameters and volumetric BMD, which may contribute to the understanding of treatment-related effects on cortical and trabecular compartments and the mechanism of action of different therapies. However, except for the small study with romosozumab, the differences between active comparators and placebo are, though statistically significant, often very small. Of note, none of the studies compared the change of the various HR-pQCT indices with the least significant change of these indices.

\section{Secondary osteoporosis and metabolic bone disorders}

HR-pQCT is increasingly used for the assessment of bone microarchitecture and bone strength in secondary osteoporosis and metabolic bone disorders to explore the pathophysiology underlying these disorders. In particular, differences in cortical and trabecular bone pathophysiology which cannot be detected by DXA are of interest. In the following prargraphs, we provide a brief overview of HR-pQCT findings in several diseases and conditions.

\section{Type 2 diabetes mellitus}

Type 2 diabetes (T2D) is associated with an increased risk of fracture, while aBMD in T2D is normal or even increased and therefore underestimates the fracture risk [88, 89]. Findings from HR-pQCT studies in T2D have been highly variable. In some, but not all, studies in postmenopausal women, Ct.Po is greater in T2D compared to controls [18, 90, 91]. In addition, lower Ct.BMD and Ct.Th have been reported, especially in the presence of microvascular disease [60,91]. In a cohort of elderly Swedish women with T2D, the majority newly diagnosed or in monotherapy with metformin, tibial, and radial trabecular bone volume fraction were higher in the diabetic group than in controls. In addition, Ct.Po were lower in a nonstandard less distal site [92]. In a study of men and women with predominantly well-controlled T2D of relatively shortterm duration, T2D was not associated with Tt.BMD, bone microarchitecture, and strength of the radius and tibia, except for smaller cross-sectional area of the tibia [93]. Less wellcontrolled T2D (HbA1c > 7\%) was associated with lower Ct.BMD and Ct.Th, higher Ct.Po and Tb.N at the radius, and higher $\mathrm{Tb} . \mathrm{N}$ and lower $\mathrm{Tb}$.Th at the tibia [93]. In addition, insulin use was negatively associated with bone density, bone micro-architectural, and bone strength parameters [94]. It was also shown that postmenopausal women with T2D duration less than 10 years had a greater plate-like trabecular network 
and in women with $\mathrm{T} 2 \mathrm{D}$ duration $\geq 10$ years, this did not differ compared to control subjects, which suggests that early advantages of trabecular plate qualities are eliminated in the later stage of T2D [95].

In summary, several studies indicated that cortical and trabecular microstructures are impaired in T2D, although these findings are not universal. This lack of consensus may be due to differences in the measured location at the radius or tibia, and/or subject heterogeneity, particularly with regard to the duration and severity of $\mathrm{T} 2 \mathrm{D}$, and the presence of microvascular complications. The question remains whether these microstructural deficits explain, at least in part, the increased fracture risk observed in T2D. Longitudinal evaluation of bone microstructure is required to describe the evolution of microarchitectural changes in T2D and its association with fracture incidence. Also, the pathogenesis of these abnormalities and their relationship to the increased fracture risk needs further study.

\section{Chronic kidney disease}

Microarchitecture is already impaired in the early stages of chronic kidney disease (CKD), with lower Tb.N and more heterogeneous distribution of trabeculae in men and women and lower Ct.Th in men compared to healthy controls [12]. Compared to stage $3 \mathrm{CKD}$, stage $4 \mathrm{CKD}$ patients had lower Tt.BMD, Ct.BMD, and Tb.BMD, lower Tb.BV/TV, Tb.N, $\mathrm{Tb}$.Th, and $\mathrm{Ct}$.Th, and increased heterogeneity of the trabecular network [96]. Salam et al. reported that distal radius HRpQCT could discriminate low bone turnover from non-low bone turnover in patients with CKD not yet on dialysis, especially when used in combination with other biomarkers such as bone specific alkaline phosphatase, PINP, and TRAP5b [97].

Compared to sex and age matched controls, female hemodialysis patients had lower Tt.BMD, Tb.BMD and Tb.N, Ct.BMD, thickness, and Ct.Ar in the radius and tibia. The reduction of these parameters correlated with the severity of secondary hyperparathyroidism, only in women [98]. Similar findings regarding cortical loss, and the association with higher PTH levels was reported in a 1.5-year longitudinal study, except for Tb.BMD and trabecular microarchitecture which did not change [99]. In one study, bone microarchitecture was less deteriorated in patients on peritoneal dialysis than on hemodialysis [100].

Marques et al. found an inverse correlation between radius Ct.BMD measured by HR-pQCT, with histomorphometric bone remodeling markers. Tb.BMD and BV/TV measured through HR-pQCT in the distal radius correlated with trabecular and mineralized trabecular bone volume. Tb.N, Tb.Sp, and $\mathrm{Tb}$.Th obtained from HR-pQCT and from bone biopsy correlated with each other. Patients with Ct.Po on bone histomorphometry presented lower Ct.BMD at the distal radius. There was an agreement between HR-pQCT and bone biopsy parameters, particularly in cortical compartment, which may point to a new perspective on the fracture risk assessment for CKD patients [101].

Although data are still limited, Ct.Po seems to be the most sensitive HR-pQCT parameter to detect changes over time in CKD. HR-pQCT imaging for Ct.Po assessment may develop as a possible clinical tool for assessment of disease progression and treatment efficacy in CKD, but prospective studies with larger cohorts are needed.

\section{Atypical femoral fracture}

Zanchetta et al. reported no differences in any of the HRpQCT parameters between postmenopausal women with or without treatment history and with or without history of atypical fractures [102]. In addition, they found no specific microarchitectural features in women who had suffered an atypical fracture of the femur while receiving bisphosphonate treatment. In contrast to the study of Zanchetta, in the study by Popp et al., treatment-naïve participants had greater Tt.Ar, Ct.Ar, Tb.N, Tb.BMD, stiffness, and failure load compared with those with an AFF [103]. Further studies are needed to examine the predictive value of microarchitectural properties and bone strength in the occurrence of AFF.

\section{Glucocorticoid-induced osteoporosis}

At a given aBMD level, patients taking corticosteroids are at higher risk for fracture than those who do not take these drugs, suggesting that some type of bone change is not captured by DXA. Only few HR-pQCT studies are available at present. In a case-control study of postmenopausal women treated with oral glucocorticoids for longer than 3 months, GC-treated women had abnormal Ct.BMD and Tb.BMD and microarchitecture at both the radius and tibia, including fewer trabecular plates, less axially aligned trabecular network, lower trabecular connectivity, thinner cortices, and lower wholebone stiffness [104]. In patients on long-term glucocorticoid treatment (mean 7.5 years), those with vertebral fracture had a lower Tt.BMD and Ct.Th independent of aBMD compared to those with no vertebral fracture [105]. Also, in women using inhaled glucocorticoids, lower Tt.BMD, Ct.BMD, and Tb.BMD at both radius and tibia were found, with lower Ct.Th and Tb.N and greater Tb.Sp and heterogeneity at the radius and greater heterogeneity at the tibia. Whole bone stiffness was lower at the radius and tended to be lower at the tibia [106].

Because of the limited number of studies and also because the underlying glucocorticoid requiring disorders such as rheumatoid arthritis, systemic lupus erythematosus (SLE), or chronic obstructive pulmonary disease (COPD) may also 
influence bone microarchitecture, the value of HR-pQCT in glucocorticoid-induced osteoporosisis is not clear yet.

\section{Rheumatoid arthritis and systemic lupus erythematosus}

Rheumatoid arthritis (RA) is a highly destructive bone disease. It is well established that RA leads to bone loss, severe pain, and functional disability of joints as well as to an increased fracture risk. Kocijan et al. showed that RA patients had decreased Tb.BV/TV at the distal and ultradistal radius caused by a decrease in Tb.N and Tb.Th. Also, lower Ct.BMD and cortical thinning, but not Ct.Po, were common in RA. The increased cortical perimeter (Ct.Pm) in RA may reflect a compensatory mechanism to counteract cortical thinning and to restore bone strength [107]. Similar results were reported in the distal radius of Chinese men with RA [108], and deterioration of microarchitecture was also reported in the head regions of the second and third metacarpal regions [109].

In patients with SLE, it has been shown cross-sectionally and longitudinally with HR-pQCT that microstructural deterioration is mainly localized in the cortical compartment and characterized by lower Ct.BMD and Ct.Th and increased Ct.Po $[13,110,111]$.

\section{Osteogenesis imperfecta}

The classical osteogenesis imperfecta (OI) types based on the clinical classification show profound differences in bone mass and architecture; these differences correlate well with the underlying biochemical and molecular collagen abnormalities. HR-pQCT revealed significant differences between patients with OI types I and IV. Patients with type I had lower Tt.BMD, thinner cortices, and reduced Tb.N compared to patients with type IV [112]. In adult patients classified as having mild OI, an age-dependent decrease in DXA Z scores was not observed, while HR-pQCT revealed a significant reduction in Tt.BMD and Tb.N in the distal radius and tibia compared to healthy controls [113]. The mild OI patients had many similarities in the microstructural parameters in comparison to patients with early osteoporosis, but without mutations in known disease genes [113].

The potential value of HR-pQCT and the lack of discriminative power of DXA in OI have led to researchers to choose Tb.BMD as the primary outcome of the recently completed phase 2 randomized trial of the sclerostin inhibitor setrusumab.

\section{Primary hyperparathyroidism}

In postmenopausal women with untreated PHPT compared with healthy controls, cortical deterioration was noted at both the radius and tibia in addition to trabecular deterioration at the radius, demonstrated by decreased Tb.N and Tb.Th in addition to increased Tb.Sp and Tb.Sp.SD [114]. Hansen et al. also noted cortical deterioration at both sites with decreased Tb.N and slightly increased Tb.Sp at the radius in a cohort of primarily postmenopausal women with untreated PHPT [115]. Post-parathyroidectomy, significant improvements in Tt.BMD, Ct.BMD, Tb.BMD, and Ct.Th were found at both the radius and tibia. There were no significant changes in trabecular microarchitectural parameters, but estimated bone strength was improved after surgery at both tibia and radius, starting at 6 months and persisting through 24 months [116].

\section{Hypoparathyroidism}

Hypoparathyroidism is an uncommon endocrine disorder characterized by chronic deficiency or absence of parathyroid hormone, leading to a reduction in bone remodeling and aBMD measurements above average at all skeletal sites, with greatest scores observed at the lumbar spine [117]. Using HRpQCT, Ct.BMD was higher and Ct.Po lower in the hypoparathyroid cohort compared with controls at the radius and tibia in premenopausal and postmenopausal women and at the tibia in young men. Tb.N was higher in premenopausal hypoparathyroid women and men, and Tb.Th was lower in women. Ultimate stress and failure load at both sites for the hypoparathyroid subjects were similar to controls $[117,118]$.

\section{Other disorders and conditions}

HR-pQCT has been used in other disorders such as celiac disease, COPD, carcinoid syndrome, hemophilia, Gaucher and Pompe disease, hypophosphatasia, and X-linked hypophosphatasia [119-126]. In addition, HR-pQCT has been used to evaluate the impact of medications known to have a deleterious effect on bone, such as aromatase inhibitors or androgen deprivation therapy $[127,128]$. Altogether, these studies demonstrate the potential of HR-pQCT to assess underlying structural defects in these rare bone disorders and in non-skeletal conditions and treatments that impact the skeletal system.

In summary, HR-pQCT has improved our understanding of the pathophysiology of bone fragility in several metabolic diseases, but we do not yet know how to translate this into clinical applications.

\section{Novel applications of HR-pQCT}

\section{Imaging of hand joints in inflammatory arthritis}

Radiographic progression in terms of development of erosion and joint space narrowing (JSN) are the key outcome measures in inflammatory arthritis trials and longitudinal 
observational studies. However, plain radiography only provides a $2 \mathrm{D}$ evaluation of a $3 \mathrm{D}$ surface, and the development of small erosions may be missed. HR-pQCT allows detection and quantification of anabolic and catabolic bone changes of peripheral joints in a 3D setting [129-133]. Members of the SPECTRA (Study grouP for xtrEme Computed Tomography in Rheumatoid Arthritis) have published on the use of this technology to assess periarticular bone changes in a variety of arthritis conditions including RA [134-137]. Recently, algorithms have been developed for detection of cortical disruptions, erosions, their volume, and also joint space width in finger joints [138-142]. Current and future studies focus on early diagnosis of bone erosions and quantification of repair and progression of these erosions associated with treatment of RA patients with synthetic and biologic disease-modifying anti-rheumatic drugs [136, 143-145]. Disadvantages of HRpQCT in particular compared to MRI are the limited coverage of just the metacarpal and possibly in a second scan of the phalangeal joints, long scan times ( $>5 \mathrm{~min}$ ) that often result in motion artefacts, and the limitation to bone-related endpoints. Important aspects of inflammatory arthritis such as bone marrow lesions or synovial fluid cannot be quantified by HRpQCT.

\section{Assessment of distal radius fracture healing}

Recent studies show that it is feasible to assess clinically relevant and significant longitudinal changes in bone density, microarchitecture, and mechanical properties at the fracture region during the healing process of stable distal radius fractures using HR-pQCT [132, 146-148]. This can be performed by measuring patients with a recent distal radius fracture with a plaster cast $[149,150]$. During follow-up of fracture healing, it appeared that early changes in Tb.BMD, Tb.Sp, and calculated torsional stiffness provided valuable information regarding the 12-week clinical outcome in terms of pain, disability, and range of motion [147]. It was also shown that fracture healing is not completed by the time the cast is removed at approximately 6 weeks post fracture. In the following 2 years, large changes occur in BMD, microarchitecture, and biomechanical parameters at the fractured side, with full recovery after 2 years in comparison to the non-fractured contralateral side [148]. Major limitations of HR-pQCT are the limited scan length and the restriction to the ultradistal radius and tibia. Whether tibial shaft fractures, an important location to study delayed healing, can be studied with the newer XtremeCT II still needs to be determined.

\section{Assessment of subchondral bone plate and cartilage thickness in the knee}

Recently, HR-pQCT was applied for the assessment of subchondral bone plate and cartilage thickness in subjects with anterior cruciate ligament reconstructions versus and uninjured controls, showing loss of trabecular bone and increased subchondral bone plate thickness in the reconstructed knees, consistent with changes associated with OA progression $[151,152]$. Also, reconstructed knees after meniscal injury demonstrated detectable differences in BMD and bone microarchitecture on HR-pQCT, despite having normal radiographs [153]. This application of HRpQCT is limited to the newer XtremeCT II device. But even with this scanner, only one leg fits into the gantry at a time and most elderly people will not be able to keep the other leg outside. Thus, while meniscal injury in younger people may be a good target application, the investigation of OA in elderly subjects probably is not. For this purpose, new cone beam CT scanners that allow scanning of both knees in standing position may be preferable.

\section{Cone beam CT}

A very similar technology to HR-pQCT is cone beam CT $(\mathrm{CBCT})$, widely used in the dental field. CBCT has recently been modified for orthopedic applications [154]. Spatial resolution is typically measured as a $10 \%$ value of the modulation transfer function (MTF) in line pairs per $\mathrm{mm}(\mathrm{lp} / \mathrm{mm})$ and should not be confused with the voxel size of the reconstructed image. For the XtremeCT I, a $10 \%$ MTF value of $3.84 \mathrm{lp} / \mathrm{mm}$ corresponding to a spatial resolution of $130 \mu \mathrm{m}$ has been published [155]. Spatial resolution of the XtremeCT II was improved by about $30 \%$, and $10 \%$ MTF values were reported to be $>$ $8.5 \mathrm{lp} / \mathrm{mm}$ by Scanco Medical, corresponding to a spatial resolution of $<60 \mu \mathrm{m}$. For CBCT and whole body CT, comparable $10 \%$ MTF values of about $1.5 \mathrm{lp} / \mathrm{mm}$ corresponding to a spatial resolution of $330 \mu \mathrm{m}$ have been reported for both modalities [156]. It should be noted that besides spatial resolution, noise is another important parameter of image quality. Also in the peripheral skeleton with a given radiation exposure, a higher spatial resolution can be obtained compared to central measurements, for example in the spine, because the thickness of tissue to be penetrated by the X-rays is much smaller and sensitivity of internal organs to radiation damage of many internal organs is higher than for bone, muscle, and fat found in the peripheral skeleton.

Compared to XtremeCT, CBCT systems offer larger scan ranges and shorter acquisition times. $\mathrm{CBCT}$ systems are smaller and less expensive, but they usually do not provide a calibrated BMD output. First applications to quantify trabecular bone architecture have shown promising results [157-159]. 


\section{Outlook and proposed clinical use}

Since the introduction of HR-pQCT imaging and the first publications in 2005, significant progress has been made towards the use of high-resolution imaging in research and potentially in clinical routine. There are still a number of obstacles for the more widespread use of HR-pQCT, primarily due to the small number of installed devices (worldwide there are fewer than 100 devices through mid-2020). As a consequence, the primary use of HR-pQCT has been so far related to research instead of broad clinical application. There are also a number of technical hurdles complicating routine clinical use:

- Most of the currently available HR-pQCT data have been collected with the first-generation XtremeCT. Although it is feasible to cross-calibrate outcomes with those of the newer XtremeCT II, results are not identical for several variables. Some study outcomes, particularly trabecular microarchitecture and cortical porosity, are not comparable between first- and second-generation devices. An automated cross-calibration between the two devices is not part of the XtremeCT II analysis software and therefore cannot be applied in clinical routine yet $[1,160]$.

- Despite reduced scan time with the XtremeCt II, motion artifacts, particularly at the radius, remain an issue. Additional work is needed to develop automated methods for detecting movement artifacts and correcting the associated scan data, if possible. Faster scan time and a larger region of interest may also be valuable.

- Standardization of HR-pQCT imaging techniques and terminology is necessary. The key recommendations for scan acquisition and analysis, quality control, training, and the standardization of reporting of results have recently been proposed [161]. Implementation of these recommendations would facilitate the clinical application of HRpQCT.

- For routine clinical use, the scan and analysis software should become more user friendly. Currently technical support is often required.

- HR-pQCT is a rather expensive technique. As a consequence, the availability of HR-pQCT devices is still limited, with most scanners installed in research environments. Clinical benefits for patient diagnosis and monitoring must be high compared to competing techniques to justify its routine use. In a recent cost-effectiveness analysis, identifying and treating women $\geq 70$ years of age with osteopenia and microstructural deterioration at the radius with zoledronate cost-effectively reduced the morbidity and mortality imposed by fragility fractures. This "targeted" approach was more cost-effective than the usual approach and incured only $25 \%$ of total costs [67]. The clinical future of HR-qQCT may therefore rely on a stepup approach. Those individuals at obviously high risk would be treated; those at low risk would not be treated, and those at intermediary risk could benefit of a second test like HR-pQCT to identify the subset with microstructural deterioration benefiting from therapy. Alternatively, if newer generation machines with quicker and fully automated analysis, along with lower prices obtained with wider distribution, the technique might be proposed as screening in primary care in countries where DXA is not well reimbursed.

The unique advantage of HR-pQCT is the high spatial resolution in vivo, which unlike any other in vivo technique, allows for the quantification of trabecular and cortical bone microarchitecture. Thus, as demonstrated in this contribution, HR-pQCT was instantaneously established as a highly valuable research tool to investigate structural aspects of bone quality. However, its value in clinical trials and in particular in routine clinical applications must be further explored. Based on our review, the following applications seem to have high potential:

- Many of the studies listed above indicate that the assessment of bone microarchitecture by HR-pQCT may improve our understanding of the mechanisms of pathophysiology in diseases such as diabetes mellitus, kidney failure, primary hyperparathyroidism, hypoparathyroidism, and osteogenesis imperfecta. In addition, HR-pQCT may also improve our understanding of the mechanisms of action of some medications known to have a deleterious effect on bone such as aromatase inhibitors or androgen deprivation therapy. Therefore, systematic studies must be conducted to determine whether these measurements could improve differential diagnosis and/or treatment monitoring of these diseases in clinical practice.

- The prospective studies, including the BOMIC pooled analysis, have shown that assessment of cortical and trabecular bone microarchitecture by HR-pQCT improves overall fracture prediction in mostly normal or osteopenic elderly subjects beyond DXA hip aBMD, but the added value was of small magnitude. In addition, it is important to note that $\mathrm{T}$ scores by DXA and HR-pQCT are not interchangeable and that at present, most clinical decision algorithms and fracture estimation tools are based on DXA T scores. The mostly unexplored potential may be the differentiation of patients with severe microstructural deterioration, which would have important implications for the decision on therapeutical interventions. Thus, besides the prediction of fracture risk, identifying subsets of bone fragility defined by specific patterns of microarchitecture/bone strength should become a new focus of HR-pQCT studies.

- The clinical use of HR-pQCT is limited by a lack of generally accepted, validated, and accessible normative data. 
Normative datasets have been published for some select populations for the first-generation HR-pQCT, but they are not part of the scanner analysis software. For the second-generation HR-pQCT, only 2 papers providing normative data in a Chinese and Canadian population are available. In particular, normative data for the microarchitectural parameters for men and women of various ethnicities and spanning the age range between 20 and 90 years are required. Collection of these data should be organized according to standardized protocols. In order to further promote the use of HR-pQCT to differentiate pathophysiological mechanisms of different diseases as suggested above, corresponding disease-specific data must also be commonly available, ideally installed as part of the scanner analysis software. Generation of these data is challenging and requires a joint effort of the HR-pQCT community.

- HR-pQCT may be included as an outcome in future clinical trials of bone drugs because it can provide insights into the mechanisms of action. In rare diseases with no possibility to conduct trials with fracture outcome, e.g., OI, this technique is instrumental. It also offers the possibility-in addition to changes in microarchitecture - to perform FEA. It should be further studied if HR-pQCT changes during the monitoring of treatment exceed the least significant change, next to the evaluation of the mean change within or the mean difference between treatment groups.

- Novel applications, such as the imaging of hand joints in inflammatory arthritis and the assessment of distal radius fracture, healing further broaden the spectrum of HRpQCT imaging and demonstrate its value beyond the field of osteoporosis. The clinical value of these new applications has yet to be demonstrated.

\section{Summary}

From the clinical perspective, challenges and prospects of more widespread use of HR-pQCT seem to be balanced. Some expert centers have integrated the use of HR-pQCT in their clinical workflow for the diagnosis of rare diseases and the quantification of bone erosions in rheumatoid arthritis. The appearance of cone beam systems that are less costly, faster, and more versatile than HR-pQCT systems has opened new areas for dedicated peripheral CT scanners, such as orthopedic applications. Standing knee CT for the investigation of osteoarthric knees is one of the promising applications. Assessment of fracture healing by these cone beam systems may compete with the HR-pQCT.

The prospects of HR-pQCT in clinical practice have to be further studied with respect to medication effects, metabolic bone disorders, rare bone diseases, and other applications such as hand joint imaging and fracture healing.

AbbreviationsStandard units Tt.BMD, Total bone mineral density (mg $\left.\mathrm{HA} / \mathrm{cm}^{3}\right) ; C t . B M D$, Cortical bone mineral density $\left(\mathrm{mg} \mathrm{HA} / \mathrm{cm}^{3}\right)$; Tb.BMD, Trabecular bone mineral density $\left(\mathrm{mg} \mathrm{HA} / \mathrm{cm}^{3}\right) ; T t . A r$, Total area $\left(\mathrm{mm}^{2}\right) ; C t . A r$, Cortical area $\left(\mathrm{mm}^{2}\right) ; C t . T h$, Cortical thickness $(\mathrm{mm})$; $C t . P o$, Cortical porosity (\%);Ct.Pm, Cortical perimeter (mm); Ct.TMD, Cortical tissue mineral density (mg HA $\left./ \mathrm{cm}^{3}\right) ; C t . P o . V$, Cortical pore volume $\left(\mathrm{mm}^{3}\right) ; T b . A r$, Trabecular area $\left(\mathrm{mm}^{2}\right) ; T b . N$, Trabecular number (1/mm); Tb.Sp, Trabecular separation (mm); Tb.Th, Trabecular thickness (mm); Tb.BV/TV, Trabecular bone volume fraction (\%); Tb.1/N.SD, Inhomogeneity of trabecular network $(\mathrm{mm})$

Acknowledgements These guidelines have been reviewed and endorsed by the Committee of Scientific Advisors of the International Osteoporosis Foundation, the American Society for Bone and Mineral Research, and the European Calcified Tissue Society.

\section{Declarations}

Conflict of interest Joop van den Bergh revceived research funding from Amgen, Eli Lilly, and UCB. Angela M. Cheung has received consultant fees from Amgen, Alexion, and Regeneron; University Health Network has received research funding from Ipsen, Mereo, and Regeneron for conduct of clinical trials. Klaus Engelke is part time employee of Bioclinica, Inc. Roland Chapurlat has received research funding from Amgen and UCB as well as consultant or speaking fees from Amgen, UCB, Kyowa-Kirin, and Eli Lilly. Pawel Szulc has no disclosures. Mary Bouxsein has no disclosures.

Open Access This article is licensed under a Creative Commons Attribution-NonCommercial 4.0 International License, which permits any non-commercial use, sharing, adaptation, distribution and reproduction in any medium or format, as long as you give appropriate credit to the original author(s) and the source, provide a link to the Creative Commons licence, and indicate if changes were made. The images or other third party material in this article are included in the article's Creative Commons licence, unless indicated otherwise in a credit line to the material. If material is not included in the article's Creative Commons licence and your intended use is not permitted by statutory regulation or exceeds the permitted use, you will need to obtain permission directly from the copyright holder. To view a copy of this licence, visit http:// creativecommons.org/licenses/by-nc/4.0/.

\section{References}

1. Agarwal S, Rosete F, Zhang C, McMahon DJ, Guo XE, Shane E, Nishiyama KK (2016) In vivo assessment of bone structure and estimated bone strength by first- and second-generation HRpQCT. Osteoporos Int 27(10):2955-2966. https://doi.org/10. 1007/s00198-016-3621-8

2. Bandirali M, Lanza E, Messina C, Sconfienza LM, Brambilla R, Maurizio R, Marchelli D, Piodi LP, Di Leo G, Ulivieri FM, Sardanelli F (2013) Dose absorption in lumbar and femoral dual energy X-ray absorptiometry examinations using three different scan modalities: an anthropomorphic phantom study. J Clin Densitom 16(3):279-282. https://doi.org/10.1016/j.jocd.2013.02. 005 
3. Engelke K, Adams JE, Armbrecht G, Augat P, Bogado CE, Bouxsein ML, Felsenberg D, Ito M, Prevrhal S, Hans DB, Lewiecki EM (2008) Clinical use of quantitative computed tomography and peripheral quantitative computed tomography in the management of osteoporosis in adults: the 2007 ISCD Official Positions. J Clin Densitom 11(1):123-162. https://doi. org/10.1016/j.jocd.2007.12.010

4. Macdonald HM, Nishiyama KK, Kang J, Hanley DA, Boyd SK (2011) Age-related patterns of trabecular and cortical bone loss differ between sexes and skeletal sites: a population-based HRpQCT study. J Bone Miner Res 26(1):50-62. https://doi.org/10. 1002/jbmr. 171

5. Hansen S, Shanbhogue V, Folkestad L, Nielsen MM, Brixen K (2014) Bone microarchitecture and estimated strength in 499 adult Danish women and men: a cross-sectional, population-based highresolution peripheral quantitative computed tomographic study on peak bone structure. Calcif Tissue Int 94(3):269-281. https://doi. org/10.1007/s00223-013-9808-5

6. Dalzell N, Kaptoge S, Morris N, Berthier A, Koller B, Braak L, van Rietbergen B, Reeve J (2009) Bone micro-architecture and determinants of strength in the radius and tibia: age-related changes in a population-based study of normal adults measured with high-resolution pQCT. Osteoporos Int 20(10):1683-1694. https://doi.org/10.1007/s00198-008-0833-6

7. Burt LA, Hanley DA, Boyd SK (2017) Cross-sectional Versus Longitudinal Change in a Prospective HR-pQCT Study. J Bone Miner Res 32(7):1505-1513. https://doi.org/10.1002/jbmr.3129

8. Alvarenga JC, Fuller H, Pasoto SG, Pereira RM (2017) Agerelated reference curves of volumetric bone density, structure, and biomechanical parameters adjusted for weight and height in a population of healthy women: an HR-pQCT study. Osteoporos Int 28(4):1335-1346. https://doi.org/10.1007/s00198-016-3876-0

9. Hung VW, Zhu TY, Cheung WH, Fong TN, Yu FW, Hung LK, Leung KS, Cheng JC, Lam TP, Qin L (2015) Age-related differences in volumetric bone mineral density, microarchitecture, and bone strength of distal radius and tibia in Chinese women: a highresolution pQCT reference database study. Osteoporos Int 26(6): 1691-1703. https://doi.org/10.1007/s00198-015-3045-x

10. Zhu TY, Yip BH, Hung VW, Choy CW, Cheng KL, Kwok TC, Cheng JC, Qin L (2018) Normative standards for HRpQCT parameters in chinese men and women. J Bone Miner Res 33(10): 1889-1899. https://doi.org/10.1002/jbmr.3481

11. Khosla S, Riggs BL, Atkinson EJ, Oberg AL, McDaniel LJ, Holets M, Peterson JM, Melton LJ 3rd (2006) Effects of sex and age on bone microstructure at the ultradistal radius: a populationbased noninvasive in vivo assessment. J Bone Miner Res 21(1): 124-131. https://doi.org/10.1359/JBMR.050916

12. Bacchetta J, Boutroy S, Vilayphiou N, Juillard L, GuebreEgziabher F, Rognant N, Sornay-Rendu E, Szulc P, Laville M, Delmas PD, Fouque D, Chapurlat R (2010) Early impairment of trabecular microarchitecture assessed with HR-pQCT in patients with stage II-IV chronic kidney disease. J Bone Miner Res 25(4): 849-857. https://doi.org/10.1359/jbmr.090831

13. Zhu TY, Griffith JF, Qin L, Hung VW, Fong TN, Au SK, Tang XL, Kun EW, Kwok AW, Leung PC, Li EK, Tam LS (2015) Cortical thinning and progressive cortical porosity in female patients with systemic lupus erythematosus on long-term glucocorticoids: a 2-year case-control study. Osteoporos Int 26(6):17591771. https://doi.org/10.1007/s00198-015-3077-2

14. Boutroy S, Bouxsein ML, Munoz F, Delmas PD (2005) In vivo assessment of trabecular bone microarchitecture by highresolution peripheral quantitative computed tomography. J Clin Endocrinol Metab 90(12):6508-6515. https://doi.org/10.1210/jc. 2005-1258

15. Burghardt AJ, Issever AS, Schwartz AV, Davis KA, Masharani U, Majumdar S, Link TM (2010) High-resolution peripheral quantitative computed tomographic imaging of cortical and trabecular bone microarchitecture in patients with type 2 diabetes mellitus. J Clin Endocrinol Metab 95(11):5045-5055. https://doi. org/10.1210/jc.2010-0226

16. Vilayphiou N, Boutroy S, Sornay-Rendu E, Van Rietbergen B, Chapurlat R (2016) Age-related changes in bone strength from HR-pQCT derived microarchitectural parameters with an emphasis on the role of cortical porosity. Bone 83:233-240. https://doi. org/10.1016/j.bone.2015.10.012

17. Macdonald HM, Nishiyama KK, Hanley DA, Boyd SK (2011) Changes in trabecular and cortical bone microarchitecture at peripheral sites associated with 18 months of teriparatide therapy in postmenopausal women with osteoporosis. Osteoporos Int 22(1): 357-362. https://doi.org/10.1007/s00198-010-1226-1

18. Burghardt AJ, Kazakia GJ, Ramachandran S, Link TM, Majumdar S (2010) Age- and gender-related differences in the geometric properties and biomechanical significance of intracortical porosity in the distal radius and tibia. J Bone Miner Res 25(5):983-993. https://doi.org/10.1359/jbmr.091104

19. Shanbhogue VV, Brixen K, Hansen S (2016) Age- and sex-related changes in bone microarchitecture and estimated strength: a threeyear prospective study using HRpQCT. J Bone Miner Res 31(8): 1541-1549. https://doi.org/10.1002/jbmr.2817

20. Kawalilak CE, Johnston JD, Olszynski WP, Kontulainen SA (2014) Characterizing microarchitectural changes at the distal radius and tibia in postmenopausal women using HR-pQCT. Osteoporos Int 25(8):2057-2066. https://doi.org/10.1007/ s00198-014-2719-0

21. Burt LA, Macdonald HM, Hanley DA, Boyd SK (2014) Bone microarchitecture and strength of the radius and tibia in a reference population of young adults: an HR-pQCT study. Arch Osteoporos 9:183. https://doi.org/10.1007/s11657-014-0183-2

22. Gabel L, Macdonald HM, Nettlefold LA, McKay HA (2018) Sex-, ethnic-, and age-specific centile curves for pQCT- and HR-pQCT-derived measures of bone structure and strength in adolescents and young adults. J Bone Miner Res 33(6):9871000. https://doi.org/10.1002/jbmr.3399

23. Burt LA, Liang Z, Sajobi TT, Hanley DA, Boyd SK (2016) Sexand site-specific normative data curves for HR-pQCT. J Bone Miner Res 31(11):2041-2047. https://doi.org/10.1002/jbmr.2873

24. Yu F, Xu Y, Hou Y, Lin Y, Jiajue R, Jiang Y, Wang O, Li M, Xing X, Zhang L, Qin L, Hsieh E, Xia W (2020) Age-, site-, and sex-specific normative centile curves for HR-pQCT-derived microarchitectural and bone strength parameters in a Chinese mainland population. J Bone Miner Res 35(11):2159-2170. https://doi.org/10.1002/jbmr.4116

25. Whittier DE, Burt LA, Hanley DA, Boyd SK (2020) Sex- and sitespecific reference data for bone microarchitecture in adults measured using second-generation HR-pQCT. J Bone Miner Res 35(11):2151-2158. https://doi.org/10.1002/jbmr.4114

26. Evans AL, Paggiosi MA, Eastell R, Walsh JS (2015) Bone density, microstructure and strength in obese and normal weight men and women in younger and older adulthood. J Bone Miner Res 30(5):920-928. https://doi.org/10.1002/jbmr.2407

27. Sornay-Rendu E, Boutroy S, Vilayphiou N, Claustrat B, Chapurlat RD (2013) In obese postmenopausal women, bone microarchitecture and strength are not commensurate to greater body weight: the Os des Femmes de Lyon (OFELY) study. J Bone Miner Res 28(7):1679-1687. https://doi.org/10.1002/jbmr. 1880

28. Singhal V, Sanchita S, Malhotra S, Bose A, Flores LPT, Valera R, Stanford FC, Slattery M, Rosenblum J, Goldstein MA, Schorr M, Ackerman KE, Miller KK, Klibanski A, Bredella MA, Misra M (2019) Suboptimal bone microarchitecure in adolescent girls with obesity compared to normal-weight controls and girls with 
anorexia nervosa. Bone 122:246-253. https://doi.org/10.1016/j. bone.2019.03.007

29. Liu CT, Sahni S, Xu H, McLean RR, Broe KE, Hannan MT, Boyd SK, Bouxsein ML, Kiel DP, Samelson EJ (2018) Long-term and recent weight change are associated with reduced peripheral bone density, deficits in bone microarchitecture, and decreased bone strength: the Framingham Osteoporosis Study. J Bone Miner Res 33(10):1851-1858. https://doi.org/10.1002/jbmr.3472

30. Popp KL, Hughes JM, Martinez-Betancourt A, Scott M, Turkington V, Caksa S, Guerriere KI, Ackerman KE, Xu C, Unnikrishnan G, Reifman J, Bouxsein ML (2017) Bone mass, microarchitecture and strength are influenced by race/ethnicity in young adult men and women. Bone 103:200-208. https://doi. org/10.1016/j.bone.2017.07.014

31. Popp KL, Xu C, Yuan A, Hughes JM, Unnikrishnan G, Reifman J, Bouxsein ML (2019) Trabecular microstructure is influenced by race and sex in Black and White young adults. Osteoporos Int 30(1):201-209. https://doi.org/10.1007/s00198-018-4729-9

32. Putman MS, Yu EW, Lin D, Darakananda K, Finkelstein JS, Bouxsein ML (2017) Differences in trabecular microstructure between black and white women assessed by individual trabecular segmentation analysis of HR-pQCT images. J Bone Miner Res 32(5):1100-1108. https://doi.org/10.1002/jbmr.3060

33. Kepley AL, Nishiyama KK, Zhou B, Wang J, Zhang C, McMahon DJ, Foley KF, Walker MD, Guo XE, Shane E, Nickolas TL (2017) Differences in bone quality and strength between Asian and Caucasian young men. Osteoporos Int 28(2): 549-558. https://doi.org/10.1007/s00198-016-3762-9

34. Wang XF, Wang Q, Ghasem-Zadeh A, Evans A, McLeod C, Iuliano-Burns S, Seeman E (2009) Differences in macro- and microarchitecture of the appendicular skeleton in young Chinese and white women. J Bone Miner Res 24(12):1946-1952. https:// doi.org/10.1359/jbmr.090529

35. Liu XS, Walker MD, McMahon DJ, Udesky J, Liu G, Bilezikian JP, Guo XE (2011) Better skeletal microstructure confers greater mechanical advantages in Chinese-American women versus white women. J Bone Miner Res 26(8):1783-1792. https://doi.org/10. 1002/jbmr.378

36. Boutroy S, Walker MD, Liu XS, McMahon DJ, Liu G, Guo XE, Bilezikian JP (2014) Lower cortical porosity and higher tissue mineral density in Chinese American versus white women. J Bone Miner Res 29(3):551-561. https://doi.org/10.1002/jbmr. 2057

37. Bala Y, Zebaze R, Ghasem-Zadeh A, Atkinson EJ, Iuliano S, Peterson JM, Amin S, Bjornerem A, Melton LJ 3rd, Johansson H, Kanis JA, Khosla S, Seeman E (2014) Cortical porosity identifies women with osteopenia at increased risk for forearm fractures. J Bone Miner Res 29(6):1356-1362. https://doi.org/10. 1002/jbmr.2167

38. Boutroy S, Khosla S, Sornay-Rendu E, Zanchetta MB, McMahon DJ, Zhang CA, Chapurlat RD, Zanchetta J, Stein EM, Bogado C, Majumdar S, Burghardt AJ, Shane E (2016) Microarchitecture and peripheral BMD are impaired in postmenopausal white women with fracture independently of total hip T-score: an international multicenter study. J Bone Miner Res 31(6):1158-1166. https:// doi.org/10.1002/jbmr.2796

39. Nishiyama KK, Macdonald HM, Hanley DA, Boyd SK (2013) Women with previous fragility fractures can be classified based on bone microarchitecture and finite element analysis measured with HR-pQCT. Osteoporos Int 24(5):1733-1740. https://doi.org/10. 1007/s00198-012-2160-1

40. Sornay-Rendu E, Boutroy S, Munoz F, Delmas PD (2007) Alterations of cortical and trabecular architecture are associated with fractures in postmenopausal women, partially independent of decreased BMD measured by DXA: the OFELY study. J Bone Miner Res 22(3):425-433. https://doi.org/10.1359/jbmr.061206
41. Sornay-Rendu E, Cabrera-Bravo JL, Boutroy S, Munoz F, Delmas PD (2009) Severity of vertebral fractures is associated with alterations of cortical architecture in postmenopausal women. J Bone Miner Res 24(4):737-743. https://doi.org/10.1359/jbmr.081223

42. Stein EM, Kepley A, Walker M, Nickolas TL, Nishiyama K, Zhou B, Liu XS, McMahon DJ, Zhang C, Boutroy S, Cosman F, Nieves J, Guo XE, Shane E (2014) Skeletal structure in postmenopausal women with osteopenia and fractures is characterized by abnormal trabecular plates and cortical thinning. J Bone Miner Res 29(5): 1101-1109. https://doi.org/10.1002/jbmr.2144

43. Stein EM, Liu XS, Nickolas TL, Cohen A, McMahon DJ, Zhou B, Zhang C, Kamanda-Kosseh M, Cosman F, Nieves J, Guo XE, Shane E (2012) Microarchitectural abnormalities are more severe in postmenopausal women with vertebral compared to nonvertebral fractures. J Clin Endocrinol Metab 97(10):E1918 E1926. https://doi.org/10.1210/jc.2012-1968

44. Stein EM, Liu XS, Nickolas TL, Cohen A, Thomas V, McMahon DJ, Zhang C, Cosman F, Nieves J, Greisberg J, Guo XE, Shane E (2011) Abnormal microarchitecture and stiffness in postmenopausal women with ankle fractures. J Clin Endocrinol Metab 96(7):2041-2048. https://doi.org/10.1210/jc.2011-0309

45. Stein EM, Liu XS, Nickolas TL, Cohen A, Thomas V, McMahon DJ, Zhang C, Yin PT, Cosman F, Nieves J, Guo XE, Shane E (2010) Abnormal microarchitecture and reduced stiffness at the radius and tibia in postmenopausal women with fractures. $\mathrm{J}$ Bone Miner Res 25(12):2572-2581. https://doi.org/10.1002/ jbmr. 152

46. Wang J, Stein EM, Zhou B, Nishiyama KK, Yu YE, Shane E, Guo XE (2016) Deterioration of trabecular plate-rod and cortical microarchitecture and reduced bone stiffness at distal radius and tibia in postmenopausal women with vertebral fractures. Bone 88: 39-46. https://doi.org/10.1016/j.bone.2016.04.003

47. Melton LJ 3rd, Riggs BL, Keaveny TM, Achenbach SJ, Kopperdahl D, Camp JJ, Rouleau PA, Amin S, Atkinson EJ, Robb RA, Therneau TM, Khosla S (2010) Relation of vertebral deformities to bone density, structure, and strength. J Bone Miner Res 25(9):1922-1930. https://doi.org/10.1002/jbmr.150

48. Biver E, Durosier C, Chevalley T, Herrmann FR, Ferrari S, Rizzoli R (2015) Prior ankle fractures in postmenopausal women are associated with low areal bone mineral density and bone microstructure alterations. Osteoporos Int 26(8):2147-2155. https:// doi.org/10.1007/s00198-015-3119-9

49. Sundh D, Nilsson AG, Nilsson M, Johansson L, Mellstrom D, Lorentzon M (2017) Increased cortical porosity in women with hip fracture. J Intern Med 281(5):496-506. https://doi.org/10. 1111/joim. 12587

50. Sundh D, Mellstrom D, Nilsson M, Karlsson M, Ohlsson C, Lorentzon M (2015) Increased cortical porosity in older men with fracture. J Bone Miner Res 30(9):1692-1700. https://doi.org/10. 1002/jbmr.2509

51. Szulc P, Boutroy S, Vilayphiou N, Chaitou A, Delmas PD, Chapurlat R (2011) Cross-sectional analysis of the association between fragility fractures and bone microarchitecture in older men: the STRAMBO study. J Bone Miner Res 26(6):13581367. https://doi.org/10.1002/jbmr.319

52. Pialat JB, Vilayphiou N, Boutroy S, Gouttenoire PJ, SornayRendu E, Chapurlat R, Peyrin F (2012) Local topological analysis at the distal radius by HR-pQCT: application to in vivo bone microarchitecture and fracture assessment in the OFELY study. Bone 51(3):362-368. https://doi.org/10.1016/j.bone.2012.06.008

53. Mikolajewicz N, Bishop N, Burghardt AJ, Folkestad L, Hall A, Kozloff KM, Lukey PT, Molloy-Bland M, Morin SN, Offiah AC, Shapiro J, van Rietbergen B, Wager K, Willie BM, Komarova SV, Glorieux FH (2020) HR-pQCT measures of bone microarchitecture predict fracture: systematic review and meta- 
analysis. J Bone Miner Res 35(3):446-459. https://doi.org/10. 1002/jbmr.3901

54. Sornay-Rendu E, Boutroy S, Duboeuf F, Chapurlat RD (2017) Bone microarchitecture assessed by HR-pQCT as predictor of fracture risk in postmenopausal women: the OFELY Study. J Bone Miner Res 32(6):1243-1251. https://doi.org/10.1002/jbmr. 3105

55. Biver E, Durosier-Izart C, Chevalley T, van Rietbergen B, Rizzoli R, Ferrari S (2018) Evaluation of radius microstructure and areal bone mineral density improves fracture prediction in postmenopausal women. J Bone Miner Res 33(2):328-337. https://doi.org/ 10.1002/jbmr.3299

56. Burt LA, Manske SL, Hanley DA, Boyd SK (2018) Lower bone density, impaired microarchitecture, and strength predict future fragility fracture in postmenopausal women: 5-year follow-up of the Calgary CaMos cohort. J Bone Miner Res 33(4):589-597. https://doi.org/10.1002/jbmr.3347

57. Ohlsson C, Sundh D, Wallerek A, Nilsson M, Karlsson M, Johansson H, Mellstrom D, Lorentzon M (2017) Cortical bone area predicts incident fractures independently of areal bone mineral density in older men. J Clin Endocrinol Metab 102(2):516524. https://doi.org/10.1210/jc.2016-3177

58. Szulc P, Boutroy S, Chapurlat R (2018) Prediction of fractures in men using bone microarchitectural parameters assessed by highresolution peripheral quantitative computed tomography - the prospective STRAMBO Study. J Bone Miner Res 33(8):1470 1479. https://doi.org/10.1002/jbmr.3451

59. Langsetmo L, Peters KW, Burghardt AJ, Ensrud KE, Fink HA, Cawthon PM, Cauley JA, Schousboe JT, Barrett-Connor E, Orwoll ES, Osteoporotic Fractures in Men Study Research G (2018) Volumetric bone mineral density and failure load of distal limbs predict incident clinical fracture independent HR-pQCT BMD and failure load predicts incident clinical fracture of FRAX and clinical risk factors among older men. J Bone Miner Res 33(7):1302-1311. https://doi.org/10.1002/jbmr.3433

60. Samelson EJ, Demissie S, Cupples LA, Zhang X, Xu H, Liu CT, Boyd SK, McLean RR, Broe KE, Kiel DP, Bouxsein ML (2018) Diabetes and deficits in cortical bone density, microarchitecture, and bone size: Framingham HR-pQCT Study. J Bone Miner Res 33(1):54-62. https://doi.org/10.1002/jbmr.3240

61. Chapurlat R, Pialat JB, Merle B, Confavreux E, Duvert F, Fontanges E, Khacef F, Peres SL, Schott AM, Lespessailles E (2017) The QUALYOR (QUalite Osseuse LYon Orleans) study: a new cohort for non invasive evaluation of bone quality in postmenopausal osteoporosis. Rationale and study design. Arch Osteoporos 13(1):2. https://doi.org/10.1007/s11657-017-0412-6

62. Chaitou A, Boutroy S, Vilayphiou N, Munoz F, Delmas PD, Chapurlat R, Szulc P (2010) Association between bone turnover rate and bone microarchitecture in men: the STRAMBO study. J Bone Miner Res 25(11):2313-2323. https://doi.org/10.1002/jbmr. 124

63. Pepe J, Biver E, Bonnet N, Herrmann FR, Rizzoli R, Chevalley T, Ferrari SL (2017) Within- and across-sex inheritance of bone microarchitecture. J Clin Endocrinol Metab 102(1):40-45. https://doi.org/10.1210/jc.2016-2804

64. Mellstrom D, Johnell O, Ljunggren O, Eriksson AL, Lorentzon M, Mallmin H, Holmberg A, Redlund-Johnell I, Orwoll E, Ohlsson C (2006) Free testosterone is an independent predictor of BMD and prevalent fractures in elderly men: MrOS Sweden. $\mathrm{J}$ Bone Miner Res 21(4):529-535. https://doi.org/10.1359/jbmr. 060110

65. Samelson EJ, Broe KE, Xu H, Yang L, Boyd S, Biver E, Szulc P, Adachi J, Amin S, Atkinson E, Berger C, Burt L, Chapurlat R, Chevalley T, Ferrari S, Goltzman D, Hanley DA, Hannan MT, Khosla S, Liu CT, Lorentzon M, Mellstrom D, Merle B, Nethander M, Rizzoli R, Sornay-Rendu E, Van Rietbergen B,
Sundh D, Wong AKO, Ohlsson C, Demissie S, Kiel DP, Bouxsein ML (2019) Cortical and trabecular bone microarchitecture as an independent predictor of incident fracture risk in older women and men in the Bone Microarchitecture International Consortium (BoMIC): a prospective study. Lancet Diabetes Endocrinol 7(1):34-43. https://doi.org/10.1016/S22138587(18)30308-5

66. Chapurlat R, Bui M, Sornay-Rendu E, Zebaze R, Delmas PD, Liew D, Lespessailles E, Seeman E (2020) Deterioration of cortical and trabecular microstructure identifies women with osteopenia or normal bone mineral density at imminent and long-term risk for fragility fracture: a prospective study. J Bone Miner Res 35(5):833-844. https://doi.org/10.1002/jbmr.3924

67. Liew D, Chapurlat RD, Sornay-Rendu E, Lespessailles E, Peng Y, Seeman E (2020) Cost-effectiveness of treatment of women aged 70 years and older with both osteopenia and microstructural deterioration. Bone 142:115682. https://doi.org/10.1016/j.bone.2020. 115682

68. Burghardt AJ, Kazakia GJ, Sode M, de Papp AE, Link TM, Majumdar S (2010) A longitudinal HR-pQCT study of alendronate treatment in postmenopausal women with low bone density: relations among density, cortical and trabecular microarchitecture, biomechanics, and bone turnover. J Bone Miner Res 25(12):2558-2571. https://doi.org/10.1002/jbmr.157

69. Folkesson J, Goldenstein J, Carballido-Gamio J, Kazakia G, Burghardt AJ, Rodriguez A, Krug R, de Papp AE, Link TM, Majumdar S (2011) Longitudinal evaluation of the effects of alendronate on MRI bone microarchitecture in postmenopausal osteopenic women. Bone 48(3):611-621. https://doi.org/10. 1016/j.bone.2010.10.179

70. Bala Y, Chapurlat R, Cheung AM, Felsenberg D, LaRoche M, Morris E, Reeve J, Thomas T, Zanchetta J, Bock O, GhasemZadeh A, Djoumessi RM, Seeman E, Rizzoli R (2014) Risedronate slows or partly reverses cortical and trabecular microarchitectural deterioration in postmenopausal women. J Bone Miner Res 29(2):380-388. https://doi.org/10.1002/jbmr. 2101

71. Chapurlat RD, Laroche M, Thomas T, Rouanet S, Delmas PD, de Vernejoul MC (2013) Effect of oral monthly ibandronate on bone microarchitecture in women with osteopenia-a randomized placebo-controlled trial. Osteoporos Int 24(1):311-320. https:// doi.org/10.1007/s00198-012-1947-4

72. Rizzoli R, Chapurlat RD, Laroche JM, Krieg MA, Thomas T, Frieling I, Boutroy S, Laib A, Bock O, Felsenberg D (2012) Effects of strontium ranelate and alendronate on bone microstructure in women with osteoporosis. Results of a 2-year study. Osteoporos Int 23(1):305-315. https://doi.org/10.1007/s00198011-1758-Z

73. Seeman E, Delmas PD, Hanley DA, Sellmeyer D, Cheung AM, Shane E, Kearns A, Thomas T, Boyd SK, Boutroy S, Bogado C, Majumdar S, Fan M, Libanati C, Zanchetta J (2010) Microarchitectural deterioration of cortical and trabecular bone: differing effects of denosumab and alendronate. J Bone Miner Res 25(8):1886-1894. https://doi.org/10.1002/jbmr.81

74. Cheung AM, Majumdar S, Brixen K, Chapurlat R, Fuerst T, Engelke K, Dardzinski B, Cabal A, Verbruggen N, Ather S, Rosenberg E, de Papp AE (2014) Effects of odanacatib on the radius and tibia of postmenopausal women: improvements in bone geometry, microarchitecture, and estimated bone strength. J Bone Miner Res 29(8):1786-1794. https://doi.org/10.1002/jbmr.2194

75. Nishiyama KK, Cohen A, Young P, Wang J, Lappe JM, Guo XE, Dempster DW, Recker RR, Shane E (2014) Teriparatide increases strength of the peripheral skeleton in premenopausal women with idiopathic osteoporosis: a pilot HR-pQCT study. J Clin Endocrinol Metab 99(7):2418-2425. https://doi.org/10.1210/jc. 2014-1041 
76. Paggiosi MA, Yang L, Blackwell D, Walsh JS, McCloskey E, Peel N, Eastell R (2018) Teriparatide treatment exerts differential effects on the central and peripheral skeleton: results from the MOAT study. Osteoporos Int 29(6):1367-1378. https://doi.org/ 10.1007/s00198-018-4445-5

77. Schafer AL, Burghardt AJ, Sellmeyer DE, Palermo L, Shoback DM, Majumdar S, Black DM (2013) Postmenopausal women treated with combination parathyroid hormone (1-84) and ibandronate demonstrate different microstructural changes at the radius vs. tibia: the PTH and Ibandronate Combination Study (PICS). Osteoporos Int 24(10):2591-2601. https://doi.org/10. 1007/s00198-013-2349-y

78. Hansen S, Hauge EM, Beck Jensen JE, Brixen K (2013) Differing effects of PTH 1-34, PTH 1-84, and zoledronic acid on bone microarchitecture and estimated strength in postmenopausal women with osteoporosis: an 18-month open-labeled observational study using HR-pQCT. J Bone Miner Res 28(4):736-745. https://doi.org/10.1002/jbmr.1784

79. Tsai JN, Uihlein AV, Burnett-Bowie SA, Neer RM, Zhu Y, Derrico N, Lee H, Bouxsein ML, Leder BZ (2015) Comparative effects of teriparatide, denosumab, and combination therapy on peripheral compartmental bone density, microarchitecture, and estimated strength: the DATA-HRpQCT Study. J Bone Miner Res 30(1):39-45. https://doi.org/10.1002/jbmr.2315

80. Tsai JN, Uihlein AV, Burnett-Bowie SM, Neer RM, Derrico NP, Lee H, Bouxsein ML, Leder BZ (2016) Effects of two years of teriparatide, denosumab, or both on bone microarchitecture and strength (DATA-HRpQCT study). J Clin Endocrinol Metab 101(5):2023-2030. https://doi.org/10.1210/jc.2016-1160

81. Tsai JN, Nishiyama KK, Lin D, Yuan A, Lee H, Bouxsein ML, Leder BZ (2017) Effects of denosumab and teriparatide transitions on bone microarchitecture and estimated strength: the DATASwitch HR-pQCT study. J Bone Miner Res 32(10):2001-2009. https://doi.org/10.1002/jbmr.3198

82. Ramchand SK, David NL, Lee H, Bruce M, Bouxsein ML, Leder BZ, Tsai JN (2020) Effects of combination denosumab and highdose teriparatide administration on bone microarchitecture and estimated strength: the DATA-HD HR-pQCT Study. J Bone Miner Res 36:41-51. https://doi.org/10.1002/jbmr.4161

83. Graeff C, Campbell GM, Pena J, Borggrefe J, Padhi D, Kaufman A, Chang S, Libanati C, Gluer CC (2015) Administration of romosozumab improves vertebral trabecular and cortical bone as assessed with quantitative computed tomography and finite element analysis. Bone 81:364-369. https://doi.org/10.1016/j.bone. 2015.07.036

84. Bonani M, Meyer U, Frey D, Graf N, Bischoff-Ferrari HA, Wuthrich RP (2016) Effect of denosumab on peripheral compartmental bone density, microarchitecture and estimated bone strength in de novo kidney transplant recipients. Kidney Blood Press Res 41(5):614-622. https://doi.org/10.1159/000447930

85. Marques IDB, Araujo M, Graciolli FG, Dos Reis LM, Pereira RMR, Alvarenga JC, Custodio MR, Jorgetti V, Elias RM, Moyses RMA, David-Neto E (2019) A randomized trial of zoledronic acid to prevent bone loss in the first year after kidney transplantation. J Am Soc Nephrol 30(2):355-365. https://doi. org/10.1681/ASN.2018060656

86. Li EK, Zhu TY, Hung VY, Kwok AW, Lee VW, Lee KK, Griffith JF, Li M, Wong KC, Leung PC, Qin L, Tam LS (2010) Ibandronate increases cortical bone density in patients with systemic lupus erythematosus on long-term glucocorticoid. Arthritis Res Ther 12(5):R198. https://doi.org/10.1186/ar3170

87. Cheung AS, Hoermann R, Ghasem-Zadeh A, Tinson AJ, Ly V, Milevski SV, Joon DL, Zajac JD, Seeman E, Grossmann M (2020) Differing effects of zoledronic acid on bone microarchitecture and bone mineral density in men receiving androgen deprivation therapy: a randomized controlled trial. J Bone Miner Res 35(10):1871-1880. https://doi.org/10.1002/ jbmr.4106

88. Starup-Linde J, Hygum K, Langdahl BL (2018) Skeletal fragility in type 2 diabetes mellitus. Endocrinol Metab (Seoul) 33(3):339351. https://doi.org/10.3803/EnM.2018.33.3.339

89. Ferrari SL, Abrahamsen B, Napoli N, Akesson K, Chandran M, Eastell R, El-Hajj Fuleihan G, Josse R, Kendler DL, Kraenzlin M, Suzuki A, Pierroz DD, Schwartz AV, Leslie WD, Bone, Diabetes Working Group of IOF (2018) Diagnosis and management of bone fragility in diabetes: an emerging challenge. Osteoporos Int 29(12):2585-2596. https://doi.org/10.1007/s00198-018-4650-2

90. Yu EW, Putman MS, Derrico N, Abrishamanian-Garcia G, Finkelstein JS, Bouxsein ML (2015) Defects in cortical microarchitecture among African-American women with type 2 diabetes. Osteoporos Int 26(2):673-679. https://doi.org/10.1007/ s00198-014-2927-7

91. Shanbhogue VV, Hansen S, Frost M, Jorgensen NR, Hermann AP, Henriksen JE, Brixen K (2016) Compromised cortical bone compartment in type 2 diabetes mellitus patients with microvascular disease. Eur J Endocrinol 174(2):115-124. https://doi.org/ 10.1530/EJE-15-0860

92. Nilsson AG, Sundh D, Johansson L, Nilsson M, Mellstrom D, Rudang R, Zoulakis M, Wallander M, Darelid A, Lorentzon M (2017) Type 2 diabetes mellitus is associated with better bone microarchitecture but lower bone material strength and poorer physical function in elderly women: a population-based study. $\mathrm{J}$ Bone Miner Res 32(5):1062-1071. https://doi.org/10.1002/jbmr. 3057

93. de Waard EAC, de Jong JJA, Koster A, Savelberg H, van Geel TA, Houben A, Schram MT, Dagnelie PC, van der Kallen CJ, Sep SJS, Stehouwer CDA, Schaper NC, Berendschot T, Schouten J, Geusens P, van den Bergh JPW (2018) The association between diabetes status, $\mathrm{HbA1c}$, diabetes duration, microvascular disease, and bone quality of the distal radius and tibia as measured with high-resolution peripheral quantitative computed tomographyThe Maastricht Study. Osteoporos Int 29(12):2725-2738. https:// doi.org/10.1007/s00198-018-4678-3

94. de Waard EAC, Driessen JHM, de Jong JJA, van Geel T, Henry RMA, van Onzenoort HAW, Schram MT, Dagnelie PC, van der Kallen CJ, Sep SJS, Stehouwer CDA, Schaper NC, Koster A, Savelberg H, Neef C, Geusens P, de Vries F, van den Bergh JPW (2017) The association between insulin use and volumetric bone mineral density, bone micro-architecture and bone strength of the distal radius in patients with type 2 diabetes - The Maastricht study. Bone 101:156-161. https://doi.org/10.1016/j.bone.2017. 05.004

95. Starr JF, Bandeira LC, Agarwal S, Shah AM, Nishiyama KK, Hu Y, McMahon DJ, Guo XE, Silverberg SJ, Rubin MR (2018) Robust trabecular microstructure in type 2 diabetes revealed by individual trabecula segmentation analysis of HR-pQCT images. J Bone Miner Res 33(9):1665-1675. https://doi.org/10.1002/jbmr. 3465

96. Paranhos-Neto FP, Lima GAC, Silva LC, Madeira M, Vieira Neto L, Mendonca LMC, Lima ICB, Delgado AG, Leite M Jr, Gomes CP, Farias MLF (2018) HR-pQCT detects alterations in bone microstructure in men with CKD stages 3 and 4, which are influenced by hormonal changes and body composition. Clin Nephrol 89(1):10-17. https://doi.org/10.5414/CN109006

97. Salam S, Gallagher O, Gossiel F, Paggiosi M, Khwaja A, Eastell R (2018) Diagnostic accuracy of biomarkers and imaging for bone turnover in renal osteodystrophy. J Am Soc Nephrol 29(5):15571565. https://doi.org/10.1681/ASN.2017050584

98. Negri AL, Del Valle EE, Zanchetta MB, Nobaru M, Silveira F, Puddu M, Barone R, Bogado CE, Zanchetta JR (2012) Evaluation of bone microarchitecture by high-resolution peripheral 
quantitative computed tomography (HR-pQCT) in hemodialysis patients. Osteoporos Int 23(10):2543-2550. https://doi.org/10. 1007/s00198-011-1890-9

99. Nickolas TL, Stein EM, Dworakowski E, Nishiyama KK, Komandah-Kosseh M, Zhang CA, McMahon DJ, Liu XS, Boutroy S, Cremers S, Shane E (2013) Rapid cortical bone loss in patients with chronic kidney disease. J Bone Miner Res 28(8): 1811-1820. https://doi.org/10.1002/jbmr.1916

100. Pelletier S, Vilayphiou N, Boutroy S, Bacchetta J, Sornay-Rendu E, Szulc P, Arkouche W, Guebre-Egziabher F, Fouque D, Chapurlat R (2012) Bone microarchitecture is more severely affected in patients on hemodialysis than in those receiving peritoneal dialysis. Kidney Int 82(5):581-588. https://doi.org/10.1038/ ki.2012.166

101. Marques ID, Araujo MJ, Graciolli FG, Reis LM, Pereira RM, Custodio MR, Jorgetti V, Elias RM, David-Neto E, Moyses RM (2017) Biopsy vs. peripheral computed tomography to assess bone disease in CKD patients on dialysis: differences and similarities. Osteoporos Int 28(5):1675-1683. https://doi.org/10.1007/s00198017-3956-9

102. Zanchetta MB, Diehl M, Buttazzoni M, Galich A, Silveira F, Bogado CE, Zanchetta JR (2014) Assessment of bone microarchitecture in postmenopausal women on long-term bisphosphonate therapy with atypical fractures of the femur. J Bone Miner Res 29(4):999-1004. https://doi.org/10.1002/jbmr.2107

103. Popp KL, Caksa S, Martinez-Betancourt A, Yuan A, Tsai J, Yu EW, Bouxsein ML (2019) Cortical bone material strength index and bone microarchitecture in postmenopausal women with atypical femoral fractures. J Bone Miner Res 34(1):75-82. https://doi. org/10.1002/jbmr.3590

104. Sutter S, Nishiyama KK, Kepley A, Zhou B, Wang J, McMahon DJ, Guo XE, Stein EM (2014) Abnormalities in cortical bone, trabecular plates, and stiffness in postmenopausal women treated with glucocorticoids. J Clin Endocrinol Metab 99(11):4231-4240. https://doi.org/10.1210/jc.2014-2177

105. Shen J, Griffith JF, Zhu TY, Tang P, Kun EW, Lee VK, Yip RM, Kwok KY, Ying SK, Ho CT, Lau SL, Pui MO, Li TK, Lau EY, Lee JJ, Qin L, Tam LS (2018) Bone mass, microstructure, and strength can discriminate vertebral fracture in patients on longterm steroid treatment. J Clin Endocrinol Metab 103(9):33403349. https://doi.org/10.1210/jc.2018-00490

106. Liu Y, Dimango E, Bucovsky M, Agarwal S, Nishiyama K, Guo XE, Shane E, Stein EM (2018) Abnormal microarchitecture and stiffness in postmenopausal women using chronic inhaled glucocorticoids. Osteoporos Int 29(9):2121-2127. https://doi.org/10. 1007/s00198-018-4591-9

107. Kocijan R, Finzel S, Englbrecht M, Engelke K, Rech J, Schett G (2014) Decreased quantity and quality of the periarticular and nonperiarticular bone in patients with rheumatoid arthritis: a cross-sectional HR-pQCT study. J Bone Miner Res 29(4):10051014. https://doi.org/10.1002/jbmr.2109

108. Zhu TY, Griffith JF, Qin L, Hung VW, Fong TN, Au SK, Li M, Lam YY, Wong CK, Kwok AW, Leung PC, Li EK, Tam LS (2014) Alterations of bone density, microstructure, and strength of the distal radius in male patients with rheumatoid arthritis: a case-control study with HR-pQCT. J Bone Miner Res 29(9): 2118-2129. https://doi.org/10.1002/jbmr.2221

109. Yang H, Yu A, Burghardt AJ, Virayavanich W, Link TM, Imboden JB, Li X (2017) Quantitative characterization of metacarpal and radial bone in rheumatoid arthritis using high resolution- peripheral quantitative computed tomography. Int $\mathbf{J}$ Rheum Dis 20(3):353-362. https://doi.org/10.1111/1756-185X. 12558

110. Tang XL, Griffith JF, Qin L, Hung VW, Kwok AW, Zhu TY, Kun EW, Leung PC, Li EK, Tam LS (2013) SLE disease per se contributes to deterioration in bone mineral density, microstructure and bone strength. Lupus 22(11):1162-1168. https://doi.org/10. 1177/0961203313498802

111. Tang XL, Qin L, Kwok AW, Zhu TY, Kun EW, Hung VW, Griffith JF, Leung PC, Li EK, Tam LS (2013) Alterations of bone geometry, density, microarchitecture, and biomechanical properties in systemic lupus erythematosus on long-term glucocorticoid: a case-control study using HR-pQCT. Osteoporos Int 24(6):18171826. https://doi.org/10.1007/s00198-012-2177-5

112. Hald JD, Folkestad L, Harslof T, Lund AM, Duno M, Jensen JB, Neghabat S, Brixen K, Langdahl B (2016) Skeletal phenotypes in adult patients with osteogenesis imperfecta-correlations with COL1A1/COL1A2 genotype and collagen structure. Osteoporos Int 27(11):3331-3341. https://doi.org/10.1007/s00198-016-36530

113. Rolvien T, Sturznickel J, Schmidt FN, Butscheidt S, Schmidt T, Busse B, Mundlos S, Schinke T, Kornak U, Amling M, Oheim R (2018) Comparison of bone microarchitecture between adult osteogenesis imperfecta and early-onset osteoporosis. Calcif Tissue Int 103(5):512-521. https://doi.org/10.1007/s00223-018-0447-8

114. Stein EM, Silva BC, Boutroy S, Zhou B, Wang J, Udesky J, Zhang C, McMahon DJ, Romano M, Dworakowski E, Costa AG, Cusano N, Irani D, Cremers S, Shane E, Guo XE, Bilezikian JP (2013) Primary hyperparathyroidism is associated with abnormal cortical and trabecular microstructure and reduced bone stiffness in postmenopausal women. J Bone Miner Res 28(5):1029-1040. https://doi.org/10.1002/jbmr.1841

115. Hansen S, Beck Jensen JE, Rasmussen L, Hauge EM, Brixen K (2010) Effects on bone geometry, density, and microarchitecture in the distal radius but not the tibia in women with primary hyperparathyroidism: A case-control study using HR-pQCT. J Bone Miner Res 25(9):1941-1947. https://doi.org/10.1002/jbmr.98

116. Cusano NE, Rubin MR, Silva BC, Tay YD, Williams JM, Agarwal S, Omeragic B, Guo XE, Bilezikian JP (2018) Skeletal microstructure and estimated bone strength improve following parathyroidectomy in primary hyperparathyroidism. J Clin Endocrinol Metab 103(1):196-205. https://doi.org/10.1210/jc. 2017-01932

117. Silva BC, Rubin MR, Cusano NE, Bilezikian JP (2017) Bone imaging in hypoparathyroidism. Osteoporos Int 28(2):463-471. https://doi.org/10.1007/s00198-016-3750-0

118. Cusano NE, Nishiyama KK, Zhang C, Rubin MR, Boutroy S, McMahon DJ, Guo XE, Bilezikian JP (2016) Noninvasive assessment of skeletal microstructure and estimated bone strength in hypoparathyroidism. J Bone Miner Res 31(2):308-316. https:// doi.org/10.1002/jbmr.2609

119. Zanchetta MB, Costa AF, Longobardi V, Mazure R, Silveira F, Temprano MP, Vazquez H, Bogado C, Niveloni SI, Smecuol E, Moreno ML, Gonzalez A, Maurino E, Zanchetta JR, Bai JC (2018) Improved bone microarchitecture in patients with celiac disease after 3 years on a gluten-free diet. Clin Gastroenterol Hepatol 16(5):774-775. https://doi.org/10.1016/j.cgh.2017.09. 054

120. Romme EA, Rutten EP, Geusens P, de Jong JJ, van Rietbergen B, Smeenk FW, Wouters EF, van den Bergh JP (2013) Bone stiffness and failure load are related with clinical parameters in men with chronic obstructive pulmonary disease. J Bone Miner Res 28(10): 2186-2193. https://doi.org/10.1002/jbmr.1947

121. Walsh JS, Newell-Price JD, DeBono M, Adaway J, Keevil B, Eastell R (2013) Circulating serotonin and bone density, structure, and turnover in carcinoid syndrome. J Clin Endocrinol Metab 98(7):2902-2907. https://doi.org/10.1210/jc.2012-4174

122. Sidhu K, Boyd SK, Khan A (2020) Impact on bone microarchitecture and failure load in a patient with type I Gaucher disease who switched from Imiglucerase to Eliglustat. Mol Genet Metab Rep 24:100606. https://doi.org/10.1016/j. ymgmr.2020.100606 
123. Lee A, Boyd SK, Kline G, Poon MC (2015) Premature changes in trabecular and cortical microarchitecture result in decreased bone strength in hemophilia. Blood 125(13):2160-2163. https://doi. org/10.1182/blood-2014-10-602060

124. Khan A, Weinstein Z, Hanley DA, Casey R, McNeil C, Ramage B, Boyd S (2013) In vivo bone architecture in pompe disease using high-resolution peripheral computed tomography. JIMD Rep 7:81-88. https://doi.org/10.1007/8904 2012146

125. Whyte MP, McAlister WH, Mumm S, Bierhals AJ (2019) No vascular calcification on cardiac computed tomography spanning asfotase alfa treatment for an elderly woman with hypophosphatasia. Bone 122:231-236. https://doi.org/10.1016/j. bone.2019.02.025

126. Colares Neto GP, Pereira RM, Alvarenga JC, Takayama L, Funari MF, Martin RM (2017) Evaluation of bone mineral density and microarchitectural parameters by DXA and HR-pQCT in 37 children and adults with X-linked hypophosphatemic rickets. Osteoporos Int 28(5):1685-1692. https://doi.org/10.1007/ s00198-017-3949-8

127. Lee SJ, Kim KM, Brown JK, Brett A, Roh YH, Kang DR, Park BW, Rhee Y (2015) Negative impact of aromatase inhibitors on proximal femoral bone mass and geometry in postmenopausal women with breast cancer. Calcif Tissue Int 97(6):551-559. https://doi.org/10.1007/s00223-015-0046-x

128. Piot A, Chapurlat RD, Claustrat B, Szulc P (2019) Relationship between sex steroids and deterioration of bone microarchitecture in older men: the prospective STRAMBO Study. J Bone Miner Res 34(9):1562-1573. https://doi.org/10.1002/jbmr.3746

129. Stach CM, Bauerle M, Englbrecht M, Kronke G, Engelke K, Manger B, Schett G (2010) Periarticular bone structure in rheumatoid arthritis patients and healthy individuals assessed by highresolution computed tomography. Arthritis Rheum 62(2):330 339. https://doi.org/10.1002/art.27252

130. Topfer D, Finzel S, Museyko O, Schett G, Engelke K (2014) Segmentation and quantification of bone erosions in highresolution peripheral quantitative computed tomography datasets of the metacarpophalangeal joints of patients with rheumatoid arthritis. Rheumatology (Oxford) 53(1):65-71. https://doi.org/10. 1093/rheumatology/ket259

131. Barnabe C, Szabo E, Martin L, Boyd SK, Barr SG (2013) Quantification of small joint space width, periarticular bone microstructure and erosions using high-resolution peripheral quantitative computed tomography in rheumatoid arthritis. Clin Exp Rheumatol 31(2):243-250

132. Geusens P, Chapurlat R, Schett G, Ghasem-Zadeh A, Seeman E, de Jong J, van den Bergh J (2014) High-resolution in vivo imaging of bone and joints: a window to microarchitecture. Nat Rev Rheumatol 10(5):304-313. https://doi.org/10.1038/nrrheum. 2014.23

133. Topfer D, Gerner B, Finzel S, Kraus S, Museyko O, Schett G, Engelke K (2015) Automated three-dimensional registration of high-resolution peripheral quantitative computed tomography data to quantify size and shape changes of arthritic bone erosions. Rheumatology (Oxford) 54(12):2171-2180. https://doi.org/10. 1093/rheumatology/kev256

134. Barnabe C, Toepfer D, Marotte H, Hauge EM, Scharmga A, Kocijan R, Kraus S, Boutroy S, Schett G, Keller KK, de Jong J, Stok KS, Finzel S, Collaboration S (2016) Definition for rheumatoid arthritis erosions imaged with high resolution peripheral quantitative computed tomography and interreader reliability for detection and measurement. J Rheumatol 43(10):1935-1940. https://doi.org/10.3899/jrheum. 160648

135. Nagaraj S, Finzel S, Stok KS, Barnabe C, Collaboration S (2016) High-resolution peripheral quantitative computed tomography imaging in the assessment of periarticular bone of metacarpophalangeal and wrist joints. J Rheumatol 43(10): 1921-1934. https://doi.org/10.3899/jrheum.160647

136. Peters M, van den Bergh JP, Geusens P, Scharmga A, Loeffen D, Weijers R, van Rietbergen B, van Tubergen A (2019) Prospective follow-up of cortical interruptions, bone density, and microstructure detected on HR-pQCT: a study in patients with rheumatoid arthritis and healthy subjects. Calcif Tissue Int 104(6):571581. https://doi.org/10.1007/s00223-019-00523-2

137. Tam LS (2016) The role of high-resolution peripheral quantitative computed tomography as a biomarker for joint damage in inflammatory arthritis. J Rheumatol 43(10):1911-1913. https://doi.org/ 10.3899/jrheum. 160645

138. Figueiredo CP, Kleyer A, Simon D, Stemmler F, d'Oliveira I, Weissenfels A, Museyko O, Friedberger A, Hueber AJ, Haschka J, Englbrecht M, Pereira RMR, Rech J, Schett G, Engelke K (2018) Methods for segmentation of rheumatoid arthritis bone erosions in high-resolution peripheral quantitative computed tomography (HR-pQCT). Semin Arthritis Rheum 47(5):611-618. https://doi.org/10.1016/j.semarthrit.2017.09.011

139. Peters M, van Tubergen A, Scharmga A, Driessen A, van Rietbergen B, Loeffen D, Weijers R, Geusens P, van den Bergh $\mathrm{J}$ (2018) Assessment of cortical interruptions in the finger joints of patients with rheumatoid arthritis using HR-pQCT, radiography, and MRI. J Bone Miner Res 33(9):1676-1685. https://doi.org/10. 1002/jbmr.3466

140. Peters M, de Jong J, Scharmga A, van Tubergen A, Geusens P, Loeffen D, Weijers R, Boyd SK, Barnabe C, Stok KS, van Rietbergen B, van den Bergh J (2018) An automated algorithm for the detection of cortical interruptions and its underlying loss of trabecular bone; a reproducibility study. BMC Med Imaging 18(1):13. https://doi.org/10.1186/s12880-018-0255-7

141. Manske SL, Brunet SC, Finzel S, Stok KS, Conaghan PG, Boyd SK, Barnabe C (2019) The SPECTRA Collaboration OMERACT Working Group: construct validity of joint space outcomes with high-resolution peripheral quantitative computed tomography. J Rheumatol 46(10):1369-1373. https://doi.org/10.3899/jrheum. 180870

142. Stok KS, Burghardt AJ, Boutroy S, Peters MPH, Manske SL, Stadelmann V, Vilayphiou N, van den Bergh JP, Geusens P, Li X, Marotte H, van Rietbergen B, Boyd SK, Barnabe C, Collaboration S (2020) Consensus approach for 3D joint space width of metacarpophalangeal joints of rheumatoid arthritis patients using high-resolution peripheral quantitative computed tomography. Quant Imaging Med Surg 10(2):314-325. https://doi. org/10.21037/qims.2019.12.11

143. Stok KS, Finzel S, Burghardt AJ, Conaghan PG, Barnabe C, Collaboration S (2017) The SPECTRA Collaboration OMERACT Special Interest Group: current research and future directions. J Rheumatol 44(12):1911-1915. https://doi.org/10. 3899/jrheum.161197

144. Yue J, Griffith JF, Xu J, Xiao F, Shi L, Wang D, Wong PCH, Li EK, Li M, Li TK, Mak WY, Zhu TY, Hung VW, Qin L, Tam LS (2018) Effect of treat-to-target strategies on bone erosion progression in early rheumatoid arthritis: An HR-pQCT study. Semin Arthritis Rheum 48(3):374-383. https://doi.org/10.1016/j. semarthrit.2018.05.001

145. Yue J, Wu D, Tam LS (2018) The role of imaging in early diagnosis and prevention of joint damage in inflammatory arthritis. Expert Rev Clin Immunol 14(6):499-511. https://doi.org/10. 1080/1744666X.2018.1476849

146. de Jong JJ, Willems PC, Arts JJ, Bours SG, Brink PR, van Geel TA, Poeze M, Geusens PP, van Rietbergen B, van den Bergh JP (2014) Assessment of the healing process in distal radius fractures by high resolution peripheral quantitative computed tomography. Bone 64:65-74. https://doi.org/10.1016/j.bone.2014.03.043 
147. Meyer U, de Jong JJ, Bours SG, Keszei AP, Arts JJ, Brink PR, Menheere P, van Geel TA, van Rietbergen B, van den Bergh JP, Geusens PP, Willems PC (2014) Early changes in bone density, microarchitecture, bone resorption, and inflammation predict the clinical outcome 12 weeks after conservatively treated distal radius fractures: an exploratory study. J Bone Miner Res 29(9):20652073. https://doi.org/10.1002/jbmr.2225

148. de Jong JJA, Heyer FL, Arts JJC, Poeze M, Keszei AP, Willems PC, van Rietbergen B, Geusens PP, van den Bergh JPW (2016) Fracture repair in the distal radius in postmenopausal women: a follow-up 2 years postfracture using HRpQCT. J Bone Miner Res 31(5):1114-1122. https://doi.org/10.1002/jbmr.2766

149. de Jong JJ, Arts JJ, Meyer U, Willems PC, Geusens PP, van den Bergh JP, van Rietbergen B (2016) Effect of a cast on short-term reproducibility and bone parameters obtained from HR-pQCT measurements at the distal end of the radius. J Bone Joint Surg Am 98(5):356-362. https://doi.org/10.2106/JBJS.O.00127

150. Whittier DE, Manske SL, Boyd SK, Schneider PS (2019) The correction of systematic error due to plaster and fiberglass casts on HR-pQCT bone parameters measured in vivo at the distal radius. J Clin Densitom 22(3):401-408. https://doi.org/10.1016/j. jocd.2018.11.005

151. Bhatla JL, Kroker A, Manske SL, Emery CA, Boyd SK (2018) Differences in subchondral bone plate and cartilage thickness between women with anterior cruciate ligament reconstructions and uninjured controls. Osteoarthr Cartil 26(7):929-939. https://doi. org/10.1016/j.joca.2018.04.006

152. Kroker A, Bhatla JL, Emery CA, Manske SL, Boyd SK (2018) Subchondral bone microarchitecture in ACL reconstructed knees of young women: a comparison with contralateral and uninjured control knees. Bone 111:1-8. https://doi.org/10.1016/j.bone.2018. 03.006

153. Kroker A, Manske SL, Mohtadi N, Boyd SK (2018) A study of the relationship between meniscal injury and bone microarchitecture in ACL reconstructed knees. Knee 25(5):746-756. https://doi.org/ 10.1016/j.knee.2018.07.004

154. Posadzy M, Desimpel J, Vanhoenacker F (2018) Cone beam CT of the musculoskeletal system: clinical applications. Insights Imaging 9(1):35-45. https://doi.org/10.1007/s13244-017-0582-1

155. Burghardt AJ, Pialat JB, Kazakia GJ, Boutroy S, Engelke K, Patsch JM, Valentinitsch A, Liu D, Szabo E, Bogado CE,
Zanchetta MB, McKay HA, Shane E, Boyd SK, Bouxsein ML, Chapurlat R, Khosla S, Majumdar S (2013) Multicenter precision of cortical and trabecular bone quality measures assessed by highresolution peripheral quantitative computed tomography. J Bone Miner Res 28(3):524-536. https://doi.org/10.1002/jbmr.1795

156. Dillenseger JP, Matern JF, Gros CI, Bornert F, Goetz C, Le Minor JM, Constantinesco A, Choquet P (2015) MSCT versus CBCT: evaluation of high-resolution acquisition modes for dentomaxillary and skull-base imaging. Eur Radiol 25(2):505-515. https://doi.org/10.1007/s00330-014-3439-8

157. Mys K, Stockmans F, Vereecke E, van Lenthe GH (2018) Quantification of bone microstructure in the wrist using conebeam computed tomography. Bone 114:206-214. https://doi. org/10.1016/j.bone.2018.06.006

158. Mys K, Varga P, Gueorguiev B, Hemmatian H, Stockmans F, van Lenthe GH (2019) Correlation between cone-beam computed tomography and high-resolution peripheral computed tomography for assessment of wrist bone microstructure. J Bone Miner Res 34(5):867-874. https://doi.org/10.1002/jbmr.3673

159. de Charry C, Boutroy S, Ellouz R, Duboeuf F, Chapurlat R, Follet H, Pialat JB (2016) Clinical cone beam computed tomography compared to high-resolution peripheral computed tomography in the assessment of distal radius bone. Osteoporos Int 27(10):30733082. https://doi.org/10.1007/s00198-016-3609-4

160. Manske SL, Davison EM, Burt LA, Raymond DA, Boyd SK (2017) The estimation of second-generation HR-pQCT from first-generation HR-pQCT using in vivo cross-calibration. J Bone Miner Res 32(7):1514-1524. https://doi.org/10.1002/jbmr. 3128

161. Whittier DE, Boyd SK, Burghardt AJ, Paccou J, Ghasem-Zadeh A, Chapurlat R, Engelke K, Bouxsein ML (2020) Guidelines for the assessment of bone density and microarchitecture in vivo using high-resolution peripheral quantitative computed tomography. Osteoporos Int 31(9):1607-1627. https://doi.org/10.1007/ s00198-020-05438-5

Publisher's note Springer Nature remains neutral with regard to jurisdictional claims in published maps and institutional affiliations. 